\title{
Inhibition of HSP90 as a Strategy to Radiosensitize Glioblastoma: Targeting the DNA Damage Response and Beyond
}

OPEN ACCESS

Edited by:

Anne Vehlow,

Technical University of Dresden,

Germany

Reviewed by:

Katalin Lumniczky,

Frédéric Joliot-Curie National Research Institute for Radiobiology

and Radiohygiene, Hungary

Anthony Chalmers,

University of Glasgow,

United Kingdom

Martin Pruschy

University Hospital Zürich, Switzerland

*Correspondence: Kirsten Lauber

kirsten.lauber@med.uni-muenchen.de

Specialty section:

This article was submitted to

Cancer Molecular Targets and Therapeutics,

a section of the journal

Frontiers in Oncology

Received: 30 September 2020 Accepted: 25 January 2021

Published: 17 March 2021

Citation:

Orth M, Albrecht V, Seidl K, Kinzel L, Unger $K$, Hess J, Kreutzer L, Sun N,

Stegen B, Nieto A, Maas J

Winssinger $N$, Friedl AA, Walch AK, Belka C, Zitzelsberger $H$, Niyazi $M$ and Lauber K (2021) Inhibition of HSP90 as

a Strategy to Radiosensitize

Glioblastoma: Targeting the DNA Damage Response and Beyond.

Front. Oncol. 11:612354.

doi: 10.3389/fonc.2021.612354
Michael Orth ${ }^{1}$, Valerie Albrecht ${ }^{1}$, Karin Seidl ${ }^{1}$, Linda Kinzel ${ }^{1}$, Kristian Unger ${ }^{2}$, Julia Hess ${ }^{2}$, Lisa Kreutzer ${ }^{2}, \mathrm{Na} \mathrm{Sun}^{3}$, Benjamin Stegen ${ }^{1,4,5}$, Alexander Nieto ${ }^{1}$, Jessica Maas ${ }^{1}$, Nicolas Winssinger ${ }^{6}$, Anna A. Friedl ${ }^{1}$, Axel K. Walch ${ }^{3}$, Claus Belka ${ }^{1,4,7}$, Horst Zitzelsberger ${ }^{2,7}$, Maximilian Niyazi ${ }^{1}$ and Kirsten Lauber ${ }^{1,4,7 *}$

${ }^{1}$ Department of Radiation Oncology, University Hospital, LMU Munich, Munich, Germany, ${ }^{2}$ Research Unit Radiation Cytogenetics, Helmholtz Center Munich, German Research Center for Environmental Health GmbH, Neuherberg, Germany, ${ }^{3}$ Research Unit Analytical Pathology, Helmholtz Center Munich, German Research Center for Environmental Health GmbH, Neuherberg, Germany, ${ }^{4}$ German Cancer Consortium, Munich, Germany, ${ }^{5}$ German Cancer Research Center, Heidelberg, Germany, ${ }^{6}$ Department of Organic Chemistry, NCCR Chemical Biology, University of Geneva, Geneva, Switzerland, ${ }^{7}$ Clinical Cooperation Group Personalized Radiotherapy in Head and Neck Cancer, Helmholtz Center Munich, Neuherberg, Germany

Radiotherapy is an essential component of multi-modality treatment of glioblastoma (GBM). However, treatment failure and recurrence are frequent and give rise to the dismal prognosis of this aggressive type of primary brain tumor. A high level of inherent treatment resistance is considered to be the major underlying reason, stemming from constantly activated DNA damage response (DDR) mechanisms as a consequence of oncogene overexpression, persistent replicative stress, and other so far unknown reasons. The molecular chaperone heat shock protein 90 (HSP90) plays an important role in the establishment and maintenance of treatment resistance, since it crucially assists the folding and stabilization of various DDR regulators. Accordingly, inhibition of HSP90 represents a multi-target strategy to interfere with DDR function and to sensitize cancer cells to radiotherapy. Using NW457, a pochoxime-based HSP90 inhibitor with favorable brain pharmacokinetic profile, we show here that HSP90 inhibition at low concentrations with per se limited cytotoxicity leads to downregulation of various DNA damage response factors on the protein level, distinct transcriptomic alterations, impaired DNA damage repair, and reduced clonogenic survival in response to ionizing irradiation in glioblastoma cells in vitro. In vivo, HSP90 inhibition by NW457 improved the therapeutic outcome of fractionated CBCTbased irradiation in an orthotopic, syngeneic GBM mouse model, both in terms of tumor progression and survival. Nevertheless, in view of the promising in vitro results the in vivo efficacy was not as strong as expected, although apart from the radiosensitizing effects HSP90 inhibition also reduced irradiation-induced GBM cell migration and tumor invasiveness. Hence, our findings identify the combination of HSP90 inhibition and radiotherapy in principle as a promising strategy for GBM treatment whose performance needs to be further optimized by improved inhibitor substances, better formulations and/or administration routes, and fine-tuned treatment sequences.

Keywords: HSP90 inhibition, HSP90i, NW457, radiosensitization, glioblastoma, radiotherapy, hypermigration 


\section{INTRODUCTION}

Glioblastoma (GBM) is the most aggressive type of primary brain tumor with a highly dismal prognosis and a 5-year overall survival of less than $5 \%$ (1). Standard treatment involves maximal safe resection-if possible-followed by radio(chemo)therapy, and maintenance chemotherapy according to the EORTC/NCIC protocol (2-5). However, treatment failure and recurrence are frequent, and the major underlying reason appears to be the high level of inherent resistance against both chemo- and radiotherapy which represents a central hallmark of this cancer entity (6-9). Moreover, recent data indicate that the degree of radioresistance further increases during therapy-particularly when radiotherapy is applied in classically fractionated regimens $(10,11)$. Adaptive processes and an overt upregulation of the DNA damage response (DDR) have been reported to be crucial driving forces in this scenario (12-16). Since alternative fractionation regimens of radiotherapy have not shown relevant improvements (17-19), and recurrence frequently occurs within the irradiated volume (20), the question arises if biological targeting of the DDR can contribute to break GBM radiation resistance. Intriguingly, the DDR relies on high molecular weight proteins and multi-protein complexes which essentially require folding assistance and stabilization by chaperones, such as heat shock protein 90 (HSP90) (21-23). Thus, HSP90 actively contributes to radioand chemoresistance of GBM and other cancer cells and represents an attractive target for biologically targeted radiosensitization, because HSP90 inhibition (HSP90i) — at least in principle-can affect multiple DDR pathways simultaneously (24-26). This was the focus of the present study for which we made use of the pochoxime-based, second generation HSP90 inhibitor NW457 with documented radiosensitizing potential in other cancer entities (27-32). We observed that diverse DDR regulators are overexpressed in human GBM cells and that their protein levels decrease upon HSP90i at low nanomolar doses which per se exhibited only limited cytotoxicity. In HSP90i-treated GBM cells, DNA damage repair was clearly impaired translating into significantly reduced clonogenic survival upon irradiation in vitro. In vivo, HSP90i augmented the therapeutic efficacy of fractionated, conebeam CT (CBCT)-based irradiation in an orthotopic GBM mouse model, although less potently than expected. Interestingly, the invasive morphology of radiotherapytreated tumors was reverted by additional HSP90i, and in vitro migration analyses confirmed that HSP90i does reduce irradiationinduced GBM hypermigration.

\section{MATERIALS AND METHODS}

\section{Cell Lines and Reagents}

The human GBM cell lines LN229 and T98G were obtained from ATCC (Manassas, VA, USA) and were cultured in Dulbecco's Modified Eagle medium (DMEM), supplemented with 10\% heatinactivated fetal calf serum, $100 \mathrm{U} / \mathrm{ml}$ penicillin, and $0.1 \mathrm{mg} / \mathrm{ml}$ streptomycin (all from ThermoScientific, Schwerte, Germany) at $37^{\circ} \mathrm{C}$ and $7.5 \% \mathrm{CO}_{2}$. The murine GBM cell line GL261 was obtained from the National Cancer Institute (NCI, Bethesda, MD,
U.S.A.) and was cultured under same conditions. All cell lines were screened to be free from mycoplasma infection, and identity of human cell lines was confirmed by short tandem repeat (STR) typing (service provided by DSMZ, Braunschweig, Germany).

The HSP90 inhibitor NW457 (epi-pochoxime F) was previously described (27-31). For in vitro experiments, a 10 $\mathrm{mM}$ stock solution was prepared in DMSO (Sigma-Aldrich, Taufkirchen, Germany) and was further diluted to $100 \mu \mathrm{M}$ with DMSO before final concentrations were adjusted in cell culture medium. Respective amounts of DMSO served as controls. For in vivo purposes, NW457 was dissolved at 100 $\mathrm{mg} / \mathrm{ml}$ in DMSO and was further diluted in $0.9 \% \mathrm{NaCl}\left(37^{\circ} \mathrm{C}\right)$, supplemented with 5\% Tween-20 (all from Sigma-Aldrich). The vehicle formulation was used as control.

\section{X-Ray Treatment In Vitro}

Irradiation of cells was done with an RS225 X-ray tube $(200 \mathrm{kV}$ and $10 \mathrm{~mA}$, Thoreaus filter, $1 \mathrm{~Gy}$ in $63 \mathrm{~s}$, Xstrahl, Camberley, Great Britain) as described (30).

\section{Quantitative Real-Time PCR (qRT-PCR)}

Profiling of mRNA expression levels was performed by quantitative realtime RT-PCR as described (32). Briefly, total RNA was extracted from cells by NucleoSpin RNA II extraction kit (Macherey \& Nagel, Dueren, Germany). 500 ng of isolated RNA were mixed with $5 \mu \mathrm{M}$ random hexamers, $5 \mu \mathrm{M}$ Oligo $(\mathrm{dT})_{18}$, $500 \mu \mathrm{M}$ dNTPs, $1 \mathrm{U} / \mu \mathrm{l}$ Ribolock RNase inhibitor, and 10 units/ $\mu \mathrm{l}$ RevertAid transcriptase (all from ThermoScientific) and subjected to reverse transcription. Twenty nanograms of cDNA were employed for Realtime PCR runs with $300 \mathrm{nM}$ primers in $1 \mathrm{x}$ Maxima SYBR Green qPCR Mastermix (ThermoScientific) on an LC480 qPCR platform (Roche Applied Science, Penzberg, Germany). Primer sequences are listed in Supplementary Table 1. Relative quantification was performed by the $\delta \delta \mathrm{C}_{\mathrm{T}}$ method. Results were normalized to a matrix of reference genes comprising $18 \mathrm{~S}$ rRNA, $\delta$-Aminolaevulinate-synthase (ALAS), and $\beta 2$-Microglobulin (B2M) and calibrated to the relative expression levels measured in primary human astrocytes (BioCat, Heidelberg, Germany). Three replicates were analyzed per cell line, and heatmaps were generated using the matrix visualization software Morpheus (https://software. broadinstitute.org/morpheus).

\section{Clonogenic Survival Assay}

Clonogenic survival was assessed by colony formation assays as described before $(30,33)$. In brief, cells were detached by Trypsin/ EDTA (ThermoScientific), counted with a Neubauer counting chamber, and seeded as single cell suspensions at defined numbers anticipating 20-100 colonies per well depending on the different irradiation doses into 6-well plates. Adherence was allowed for 4 h. LN229 and T98G cells were treated with 10 nM NW457 or DMSO for $24 \mathrm{~h}$, irradiated, and incubated in the presence of $10 \mathrm{nM}$ NW457 for $13 \mathrm{~d}$. GL261 cells were treated in a similar fashion, except that NW457 was removed by medium exchange after the $24 \mathrm{~h}$ of pre-incubation. Colonies were stained with methylene blue (dissolved at $0.3 \%$ in $80 \%$ ethanol, both from Merck, Darmstadt, Germany), and all colonies containing more than 50 cells were counted under a Stemi 305 stereomicroscope 
(Carl Zeiss, Oberkochen, Germany). The percentages of surviving cells were determined and calibrated to the corresponding plating efficiencies. Regression was performed according to the linearquadratic model.

\section{Viability Assay}

Viability was determined by Alamar Blue assays (BioRad, Puchheim, Germany) as described (30). Briefly, 5,000 cells were seeded into 96-well plates, adherence was allowed for $4 \mathrm{~h}$, and cells were treated with NW457 at the indicated doses. Upon incubation for 24-96 h, medium was replaced by fresh medium supplemented with $1 / 10$ volume of Alamar Blue reagent, and Resazurin conversion was allowed at $37^{\circ} \mathrm{C}$ and $7.5 \% \mathrm{CO}_{2}$ for $2-6$ h. Resorufin fluorescence was measured on a Synergy $\mathrm{Mx}$ microplate reader platform (BioTek, Bad Friedrichshall, Germany), and results were calibrated to untreated controls.

\section{Quantitative Fluorescence Microscopy}

DNA damage repair was examined by immunofluorescence staining of phosphorylated histone variant $\mathrm{H} 2 \mathrm{AX}(\gamma \mathrm{H} 2 \mathrm{AX})$ and p53-binding protein 1 (53BP1), followed by quantitative fluorescence microscopy as described (32). Cells were seeded into 24-well plates supplemented with coverslips, allowed to adhere overnight, and treated with $10 \mathrm{nM} \mathrm{NW} 457$ or DMSO for $24 \mathrm{~h}$ before being irradiated at $2 \mathrm{~Gy}$. At the indicated time points, cells were fixed with $3.7 \%$ isotonic paraformaldehyde (Merck), containing $0.1 \%$ Triton X-100 (v/v Sigma-Aldrich) for $10 \mathrm{~min}$ before being permeabilized with $0.5 \%$ isotonic Triton X-100 for 5 min. Unspecific binding sites were blocked with 3\% isotonic bovine serum albumin (w/v, Sigma-Aldrich) and $0.1 \%$ Triton X100 at $4^{\circ} \mathrm{C}$ overnight. Cells were stained with monoclonal mouse anti- $\gamma \mathrm{H} 2 \mathrm{AX}$ (Merck Millipore) and polyclonal rabbit anti-53BP1 (Bio-Techne, Wiesbaden, Germany) antibodies diluted in 3\% isotonic bovine serum albumin and $0.1 \%$ Triton $\mathrm{X}-100$ for $2 \mathrm{~h}$ at room temperature. After extensive washing with PBS plus $0.1 \%$ Triton X-100, cells were stained with Alexa488-coupled goatanti-mouse IgG and Alexa568-coupled goat-anti-rabbit IgG (both from ThermoScientific) for $1 \mathrm{~h}$. DNA was stained with 2 $\mu \mathrm{g} / \mathrm{ml}$ Hoechst 33342 (Sigma Aldrich) for $10 \mathrm{~min}$. Upon several washing steps with PBS plus $0.1 \%$ Triton X-100, coverslips were mounted with $4 \mu \mathrm{l}$ mounting medium (Sigma-Aldrich) onto object slides. Microscopic analysis was performed with a Zeiss AxioObserver Z1 inverted microscope, equipped with an LCI Plan-Neofluar 63x/1.3 glycerol objective, an AxioCam MR Rev3 camera, and ZEN 2.3 software (all from Carl Zeiss). For image acquisition, $31 \mathrm{z}$-stacks with $250 \mathrm{~nm}$ interstack distance were captured, and deconvolution was performed with ZEN 2.3 software. For quantification of DNA damage repair, $\gamma \mathrm{H} 2 \mathrm{AX} /$ 53BP1 double-positive foci were used. At least 20 nuclei of nondeformed morphology were selected for each condition, and foci were counted by hand. Results are depicted as individual data points with superimposed means and $95 \%$ confidence intervals.

\section{Live-Cell Microscopy of Cell Death Morphology}

For live-cell imaging, a Zeiss AxioObserver Z1 inverted microscope, equipped with an AxioCam MR Rev3 camera, an
XL multi S1 incubation chamber, and a PS1 compact heating unit (both from Pecon, Erbach, Germany) was used. Briefly, cells were seeded into Ibidi $\mu$-slides (Ibidi GmbH, Martinsried, Germany) and allowed to adhere for $4 \mathrm{~h}$ before treatment with $10 \mathrm{nM}$ NW457 or DMSO for $24 \mathrm{~h}$ and irradiation at 4 Gy. Livecell imaging was initiated $1 \mathrm{~h}$ after irradiation and performed over $12 \mathrm{~d}$. Images were captured in 12 min intervals, and movies were processed with Fiji software.

\section{Wound Healing Assay}

Migration of GBM cells was assessed by wound healing assays. Cells were seeded into Ibidi $\mu$-slides supplemented with culture inserts (both from Ibidi) and allowed to adhere overnight. Cells were treated with $30 \mathrm{nM}$ NW457 or DMSO for $24 \mathrm{~h}$, irradiated at $3 \mathrm{~Gy}$, and live-cell imaging was performed for $12 \mathrm{~h}$. Images were captured in intervals of $3 \mathrm{~min}$, and cell migration was analyzed using the manual tracking plugin tool (Image) as previously described $(31,34)$. Migration was quantified in form of colonized area (four regions of interest per condition in three independent experiments) and accumulated distance per cell over time (at least 25 randomly picked cells per condition).

\section{SDS-PAGE and Western Blot}

Reducing gradient SDS-PAGE and western blot analyses of whole cell lysates (20-400 $\mu \mathrm{g}$ total protein per lane) were performed as described before $(30,35)$. Briefly, cells were lysed in lysis buffer (50 mM Tris- $\mathrm{HCl} \mathrm{pH} \mathrm{7.6,} 150 \mathrm{mM} \mathrm{NaCl}, 1 \%$ Triton X-100 (v/v) (all from Sigma Aldrich), 1 x EDTA-free protease inhibitor cocktail (Roche)), protein concentrations were measured by Bradford assay (BioRad, Feldkirchen, Germany), and 20 - or $400 \mu \mathrm{g}$ of total protein were subjected to gradient (4$15 \%$ or $6-15 \%)$ SDS-PAGE. Proteins were transferred onto PVDF Immobilon FL membranes (Merck Millipore), membranes were blocked with 5\% low-fat milk powder (Carl Roth, Karlsruhe, Germany), dissolved in TBST buffer ((13 mM Tris- $\mathrm{HCl} \mathrm{pH}$ 7.5, $150 \mathrm{mM} \mathrm{NaCl}, 0.02 \%$ Triton X-100 (v/v)), and incubated with primary antibodies at $4^{\circ} \mathrm{C}$ overnight. Primary antibodies used for western blot analyses were: Rabbit-antiATM, rabbit anti-ATR, rabbit-anti-FANCA, mouse-antiRAD51 (Merck Millipore), mouse-anti-CHK1, mouse-antiVinculin, mouse-anti- $\alpha$-tubulin (Sigma-Aldrich), rabbit-anti-KU70, rabbit-anti-XRCC3, rabbit-anti-MGMT (Biozol, Eching, Germany), mouse-anti-CHK2, mouse-anti-B-Raf (BD Transduction Laboratories, Heidelberg, Germany), rabbit-anti-RPA1, rabbit-antiRBBP8 (Biomol, Hamburg, Germany), rabbit-anti-KU80, rabbitanti-DNA2 (Thermo Scientific), rabbit-anti-p53 (Cell Signaling, Leiden, Netherlands), rabbit-anti-DNA-PKcs (Abcam, Berlin, Germany), mouse-anti-NHEJ1 (Santa Cruz, Heidelberg, Germany), rabbit-anti-LIG4 (Origene, Herford, Germany), and mouse-anti-HSP70 (BD Biosciences). Upon washing with TBST, membranes were incubated with IRDye800-conjugated secondary antibodies (LI-COR Biosciences, Bad Homburg, Germany) for $1 \mathrm{~h}$ at room temperature. Measurements and quantifications of IR800 dye fluorescence were performed with an ODYSSEY scanner (LICOR Biosciences, Bad Homburg, Germany). Relative signal intensities were normalized to a matrix of vinculin and $\alpha$ tubulin, calibrated to the untreated controls, and heatmaps were 
visualized using the matrix visualization software Morpheus (https://software.broadinstitute.org/morpheus).

\section{Transcriptome Analysis Via RNA Sequencing}

Transcriptome profiling was performed by 3'-RNA sequencing. Prior to sequencing, RNA integrity was assessed using the Agilent Bioanalyzer RNA 6000 Nano Kit (Agilent Technologies, Waldbronn, Germany) by calculating the percentage of fragments $>200$ nucleotides (DV200). Sequencing libraries were prepared with 100 ng total RNA using the QuantSeq 3'-RNA-Seq Library Prep Kit FWD for Illumina (Lexogen GmbH, Vienna, Austria) according to the manufacturer's instructions for singleindexing and good RNA quality. For library amplification, PCR cycles were determined using the PCR Add-on Kit for Illumina (Lexogen), and the individual libraries were amplified with 17 PCR cycles. Quantity and quality of sequencing libraries were assessed using the Quanti-iT PicoGreen dsDNA Assay Kit (ThermoScientific) and the Bioanalyzer High Sensitivity DNA Analysis Kit (Agilent Technologies). Libraries were sequenced in 150 bp paired-end mode on a HiSeq4000 sequencer (Illumina, Berlin, Germany). The pool of individually barcoded libraries was distributed across the lanes of the same flow-cell aiming for approximately ten million paired-end reads per sample.

For sequence data processing, adapter sequences were removed using BBDUk (https://jgi.doe.gov/data-and-tools/ bbtools). Human fastq-files including forward-reads were subjected to alignment against the human genome reference genome (GRCh38) using STAR (36). Aligned reads were quantified via htseq-count employing appropriate transcriptome gtf-files (37). FastQC was utilized for analyzing quality of unaligned and aligned reads (https://www.bioinformatics. babraham.ac.uk/projects/fastqc/) followed by summarization via multiQC (https://multiqc.info). Genes with a raw read count (for the whole dataset) smaller than five times the total number of samples were excluded. Correlation heatmaps were employed to analyze data consistency and technical outlier detection, and shrinked (apeglm) log2 expression values were determined (38). Calculation of differentially expressed genes and geneset enrichment analyses (GSEAs) were performed on the basis of $\log 2$ expression values (39). Reactome functional interaction (FI) networks were constructed and analyzed in Cytoscape $(40,41)$. iRegulon was employed to identify potential transcriptional regulators (42).

\section{Orthotopic Mouse Glioblastoma Model and Contrast-Enhanced, Conebeam CT-Based, Fractionated Radiotherapy}

All animal experiments were performed in accordance with the FELASA guidelines and upon ethical approval by the Regierung von Oberbayern. Female C57BL/6 mice were obtained from Charles River (Sulzfeld, Germany), and housed in groups of maximally four animals in individually ventilated cages (GM500, Tecniplast, Hohenpeißenberg, Germany) in a specified, pathogen-free animal facility with a $12 \mathrm{~h}$ day/night cycle. Standard rodent feed (from Ssniff, Soest, Germany) and water were provided ad libitum. Animals were inspected on a daily basis and sacrificed when reaching pre-defined health scores. Criteria for immediate sacrifice comprised the following: Strongly altered hygiene behavior, flattened breathing, body weight loss of $\geq 20 \%$, ulcerating wounds, epileptic seizures or spasms, paralysis of extremities, bloody diarrhea, apathy, hunchbacked posture, self-mutilation, isolation from the group. In milder occurrence of these criteria, mice were sacrificed within $48 \mathrm{~h}$. Intracranial implantation of GL261 cells was performed as described recently (43). Briefly, mice were medicated with 200 $\mu \mathrm{g} / \mathrm{g}$ metamizol (WDT, Garbsen, Germany) and anesthetized by intraperitoneal injection of $100 \mu \mathrm{g} / \mathrm{g}$ ketamine and $10 \mu \mathrm{g} / \mathrm{g}$ xylazine (both from WDT). Mouse heads were mounted onto a stereotaxic frame (David Instruments, Tujanga, CA, USA), skulls were exposed by longitudinal skin incision, and a hole was drilled $1.5 \mathrm{~mm}$ laterally (right) and $1 \mathrm{~mm}$ anteriorly to the bregma using a pair of $23 \mathrm{G}$ and $21 \mathrm{G}$ microlances (BD Biosciences). Then, 90,000 GL261 cells (in $1 \mu \mathrm{l}$ PBS) were slowly injected into the right striatum, using a stereotactically guided syringe (Hamilton, Bonaduz, Switzerland). Once the syringe was withdrawn, skin was closed with Ethibond Excel 5-0 suture material (Ethicon, Norderstedt, Germany), and mice were monitored until regaining consciousness. Starting at d7 after implantation, tumor growth was monitored by contrast-enhanced, conebeam computed tomography (CBCT) scans twice weekly using the small animal radiation research platform (SARRP, X-Strahl, Camberley, Great Britain) (44). For acquisition of CBCT scans, 360 projection images were captured ( $1^{\circ}$ per image, $x$-ray tube settings: $60 \mathrm{kV}$, $0.8 \mathrm{~mA}, 1.0 \mathrm{~mm}$ aluminium filter). To enhance the contrast of soft tissue, $300 \mu$ Imeron-300 (Bracco, Konstanz, Germany) were administered intravenously before CBCT scanning. Irradiation was performed at a weekdaily fractionation regimen of 2 Gy $(2 \times$ $5 \times 2$ Gy in total) with two contralateral beams (gantry positions $90^{\circ}$ and $90^{\circ}$ ) and $3 \times 9 \mathrm{~mm}^{2}$ collimation (fixed nozzle, x-ray tube settings: $220 \mathrm{kV}, 13 \mathrm{~mA}, 0.15 \mathrm{~mm}$ copper filter) on d7-11 and d1418. Isocenters were aligned to the centers of contrast enriching volumes, and treatment planning was executed with Muriplan software (X-Strahl). NW457 was administered intraperitoneally at $10 \mu \mathrm{g} / \mathrm{g}$ or $50 \mu \mathrm{g} / \mathrm{g} 24 \mathrm{~h}$ before irradiation. Tumor volumes were determined by $\mathrm{Lx} \mathrm{Wx} \mathrm{H}$ measurements of the 3 longest orthogonal axes as described (43), and $3 \mathrm{D}$ reconstructions were generated in 3D-Slicer (www.slicer.org/).

\section{Histological Analyses}

For histological analyses, mice were anesthetized by intraperitoneal injection of $50 \mu \mathrm{g} / \mathrm{g}$ pentobarbital (WDT), followed by cardial perfusion with $3.5 \%$ paraformaldehyde (Sigma-Aldrich) as described (43). Then, brains were explanted and fixed with $3.5 \%$ paraformaldehyde for $48 \mathrm{~h}$ at $4^{\circ} \mathrm{C}$. Brains were dehydrated for $48 \mathrm{~h}$ in $30 \%$ sucrose (Sigma-Aldrich), embedded in NEG-50 frozen section medium (ThermoScientific) and stored until analysis at $-80^{\circ} \mathrm{C}$. Slices of $40 \mu \mathrm{m}$ thickness were prepared with a Microm HM355S microtom (ThermoScientific), stored in cryopreserving solution $\left(200 \mathrm{mM} \mathrm{Na}_{2} \mathrm{HPO}_{4}, 200 \mathrm{mM} \mathrm{KH}_{2} \mathrm{PO}_{4}, 25 \%\right.$ ethylenglycol (v/v), 25\% glycerol (v/v) (all from Sigma Aldrich)) at $-20^{\circ} \mathrm{C}$, before being stained with Mayer's hematoxylin and eosin (both from Merck) for 1 min each. After dehydration in 70, 96, and $100 \%$ ethanol, and xylene, slices were mounted onto microscope slides 
using Entellan (Merck). Microscopic analysis was performed on an AxioLab A.1 microscope, equipped with an AxioCam Erc5s camera and AxioVision 4.9 software (all from Carl Zeiss).

\section{Statistical Analyses}

Statistical analyses were performed using OriginPro 9.1 software (OriginLab Ltd., Northhampton, MA, USA). Results are shown as individual data points of all replicates, means \pm s.d., or means $\pm 95 \%$ confidence intervals as indicated. For group comparisons, two-sided Student's $t$-tests or ANOVAs (one-way or two-way) were employed as indicated. Survival analyses were performed according to Kaplan-Meier with log-rank testing.

\section{RESULTS}

\section{HSP90 Inhibition by NW457 Leads to Downregulation of DNA Damage Response Factors on the Protein Level, Impaired DNA Damage Repair, and Reduced Clonogenic Survival in Response to lonizing Irradiation in Glioblastoma Cells}

A high degree of inherent radioresistance belongs to the signature hallmarks of $\operatorname{GBM}(6,8)$. On the molecular level, GBM radioresistance is considered to derive from constantly activated DNA damage response (DDR) mechanisms driven by the overexpression of oncogenes, persistent replicative stress, and other so far unknown reasons $(45,46)$. Previous studies have shown that HSP90 plays an important role in DDR function via its crucial involvement in folding and stabilizing DDR proteins and/or multi-protein complexes $(21,22)$. Accordingly, the present study was designed to examine whether HSP90 inhibition (HSP90i) can efficiently sensitize experimental model systems of GBM to ionizing irradiation in vitro and in vivo as a multi-target approach of pharmacological interference with the $\operatorname{DDR}(26,47,48)$. For our study, we made use of two human and one mouse GBM cell line with distinct alterations in the loci of TP53, MGMT, CDKN2A, PTEN, and IDH1/2 as described for primary GBM (Table 1) (51, 52). Initial qRT-PCR profiling confirmed that the human GBM cell lines LN229 and T98G show a broad-range upregulation of diverse DDR regulators as compared to normal human astrocytes suggesting that DDR activity is indeed increased-irrespective of the O6methylguanine-DNA-methyltransferase (MGMT) status (Figure 1A and Supplementary Figure 1A) (53). The highest levels of overexpression were detected for the replication and DDRassociated nucleases FEN1 and EXO1, members of the DNA double-strand break (DSB) detecting MRN complex (MRE11 and NBN), the DNA helicases BLM and PALB2, the singlestrand binding protein RPA1, and members of the XRCC family which are involved in non-homologous end joining (XRCC4 and XRCC6) and alternative non-homologous end joining (XRCC1).

We then tested whether HSP90i can interfere with DDR overexpression and treated the cells with NW457, a pochoximederived HSP90 inhibitor with documented radiosensitizing potential and improved pharmacokinetic profile $(27-30,32)$.
TABLE 1 | Characteristics of the GBM cell lines used in the present study.

\begin{tabular}{|c|c|c|c|}
\hline Cell Line & LN229 & T98G & GL261 \\
\hline Species & Human & Human & Mouse \\
\hline Sex & Female & Male & $\begin{array}{l}\text { No Y } \\
\text { chromosome } \\
\text { detectable }\end{array}$ \\
\hline Age & 60 years & 61 years & - \\
\hline MGMT status & $\begin{array}{l}\text { Promoter } \\
\text { methylated, mRNA } \\
\text { not detectable }\end{array}$ & $\begin{array}{l}\text { Promoter not } \\
\text { methylated, mRNA } \\
\text { detectable }\end{array}$ & $\begin{array}{l}\text { mRNA weakly } \\
\text { detectable }\end{array}$ \\
\hline IDH1/2 status & Wildtype & Wildtype & Wildtype \\
\hline TP53 status & $\begin{array}{l}\text { P98L mutation } \\
\text { Function unclear }\end{array}$ & $\begin{array}{l}\text { M237I mutation } \\
\text { Dominant negative }\end{array}$ & $\begin{array}{l}\text { R153P mutation } \\
\text { Dominant } \\
\text { negative }\end{array}$ \\
\hline CDKN2A status & Null & Null & Null \\
\hline PTEN status & Wildtype & L42R & Wildtype \\
\hline
\end{tabular}

Data were compiled from Ishii et al. (49), Cellosaurus (50), ATCC, and own unpublished data

Time course westernblot analyses of diverse DDR proteins revealed different clusters of responses in LN229 and T98G cells with several common motifs (Figure 1B). Whereas the protein levels of few individual DDR regulators, such as NBN and RBBP8, increased upon HSP90i by NW457, clearly more candidates were downregulated, including a core cluster of CHK1, RAD51, and DNA2 with a particularly strong decrease in protein levels. Other downregulated DDR proteins comprised NHEJ1, KU80, XRCC3, ATR, CHK2, LIG4, and RPA1, and for some candidates mixed responses were observed. Our findings confirm and complement previous reports showing the critical dependence of certain DDR regulators on HSP90 chaperoning function (54-56). However, our data disclose also several DDR factors with so far unknown HSP90 dependence, including DNA2, an end resecting DNase with important functions in replication and DSB repair (57-60), and NHEJ1, a scaffold protein that binds to and assists DNA ligase 4 (LIG4) in DSB repair (61). Overall, HSP90i affected proteins of various DDR pathways - at least in the GBM cell lines used in our study - thereby providing a strong rationale for combined modality approaches of HSP90i and radiotherapy. Importantly, downregulation of DDR proteins occurred already at very low concentrations of NW457 (10 nM) which per se exhibited only marginal cytotoxicity even during prolonged treatment-a characteristic which is of special interest for potential future clinical translation (Supplementary Figure 1B). These findings confirm the notion that DDR regulators, compared to other HSP90 client proteins, are particularly sensitive towards HSP90i (22).

In order to examine the consequences of HSP90i on DDR function, LN229 and T98G cells were pre-treated with NW457 for $24 \mathrm{~h}$, irradiated at $2 \mathrm{~Gy}$, and subjected to immunofluorescence staining for phosphorylated histone $\mathrm{H} 2 \mathrm{AX}(\gamma \mathrm{H} 2 \mathrm{AX})$ and 53BP1. The kinetics of DNA damage foci formation and clearance was quantitatively analyzed (Figures 1C, D). HSP90i by NW457 resulted in significantly delayed clearance of $\gamma \mathrm{H} 2 \mathrm{AX} / 53 \mathrm{BP} 1$ double-positive foci, indicating that DNA repair was obviously impaired. HSP90i also increased the overall numbers of foci as compared to the controls. This could either be due to false repair of irradiation-induced DNA damages, or irradiation-independent formation of damage sites. So far, our data show that HSP90i by 


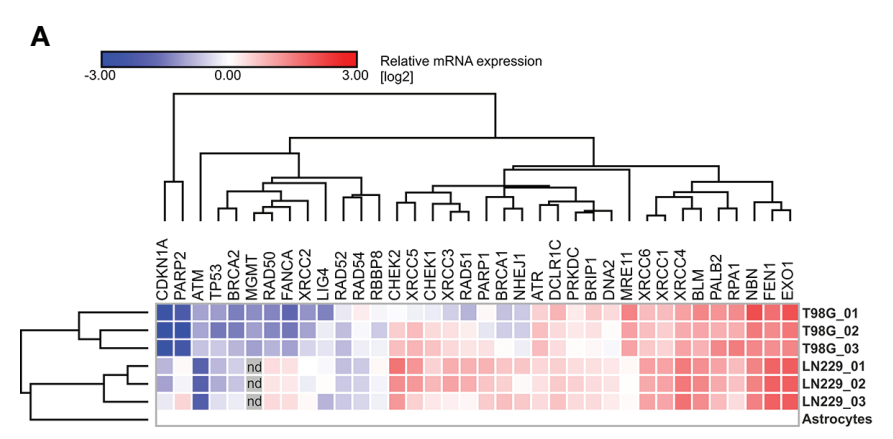

B

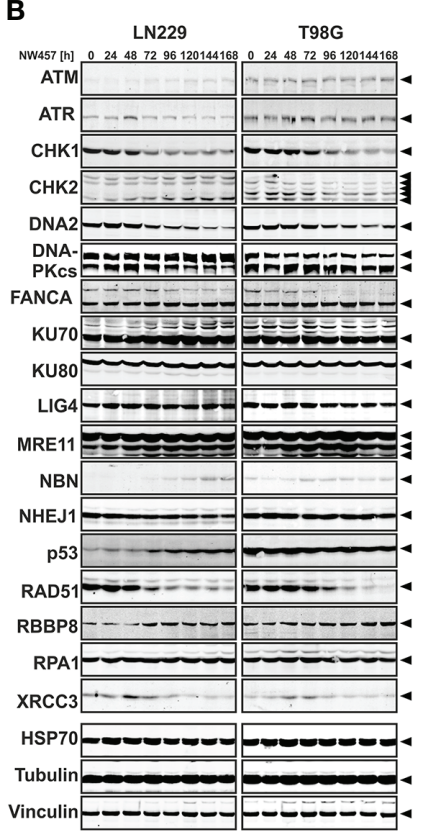

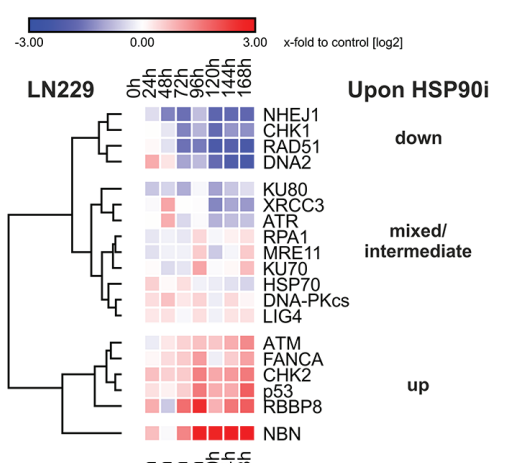

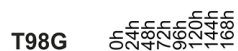

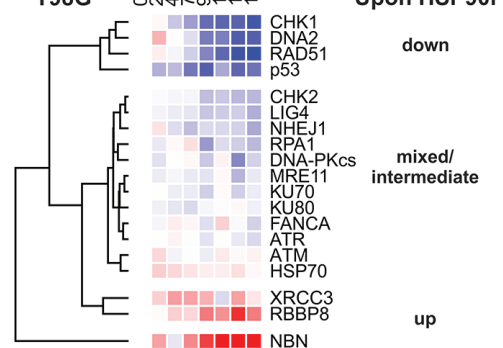

C

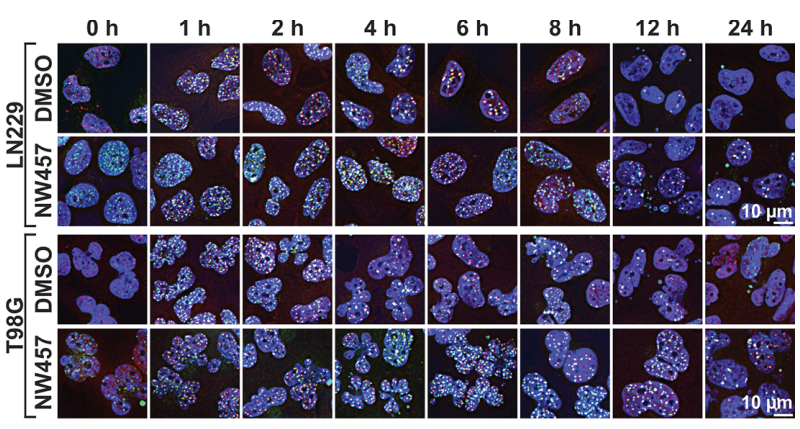

D

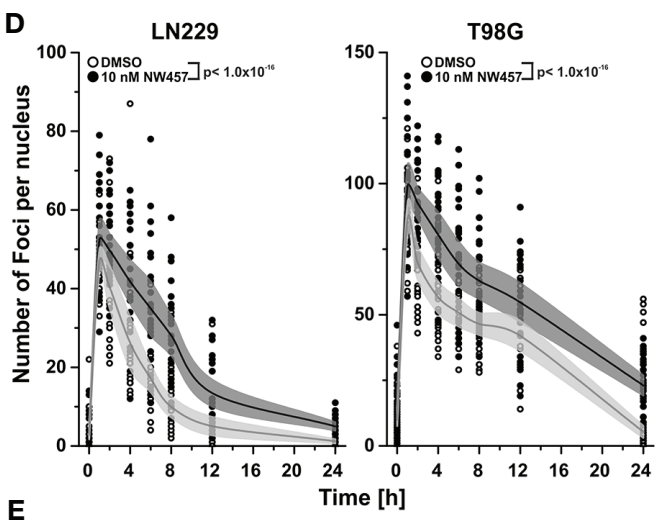

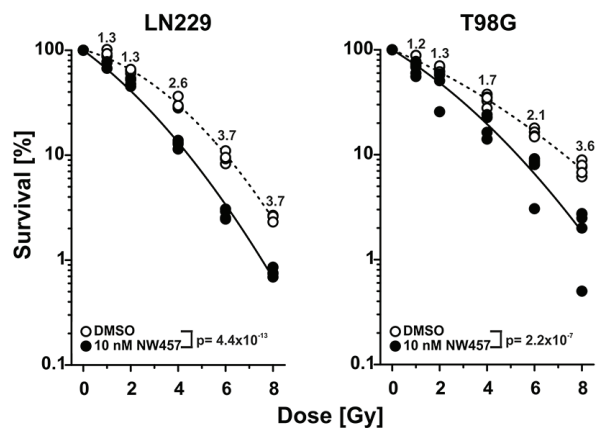

FIGURE 1 | HSP90i by NW457 leads to downregulation of DNA damage response factors, impaired DNA damage repair, and reduced clonogenic survival in response to ionizing irradiation in human glioblastoma cells. (A) Transcriptomic profiling of regulators of the DNA damage response (DDR) in LN229 and T98G cells. mRNA expression levels were determined by qRT-PCR, normalized to a matrix of 3 reference genes (18S rRNA, $\delta$-amino-laevulinate-synthase, and $\beta 2$ -

microglobulin), and calibrated to the results of untransformed human astrocytes. For both cell lines, three replicates were analyzed and are displayed as $\mathrm{x}$-fold log2values. (B) Time course analysis of DDR regulator protein expression in LN229 and T98G cells upon HSP90i by 10 nM NW457. Arrowheads indicate the bands that were used for quantification. Protein levels were normalized to a matrix comprising vinculin and $\alpha$-tubulin and are depicted as $\mathrm{x}$-fold log2-values compared to the $0 \mathrm{~h}$ controls. (C) Immunofluorescence microscopy of $\gamma \mathrm{H} 2 \mathrm{AX}$ and 53BP1 DNA damage repair foci in LN229 and T98G cells upon irradiation at 2 Gy \pm HSP90i by NW457. Cells were treated with NW457 (10 nM) or DMSO for $24 \mathrm{~h}$, irradiated, and fixed at the indicated times. Cells were stained for $\gamma \mathrm{H} 2 \mathrm{AX}$, 53BP1, and DNA and subjected to deconvolution immunofluorescence microscopy. Scale bar depicts $10 \mu \mathrm{m}$. (D) Quantification of DNA damage repair kinetics from (C). $\gamma \mathrm{H} 2 \mathrm{AX}$ and 53BP1 double-positive foci in at least 20 randomly picked nuclei were counted by hand. Individual data points with superimposed means $\pm 95 \%$ confidence intervals are displayed, and overall curve comparison was performed by two-way ANOVA. (E) Clonogenic survival of LN229 and T98G cells upon irradiation at 0-8 Gy \pm

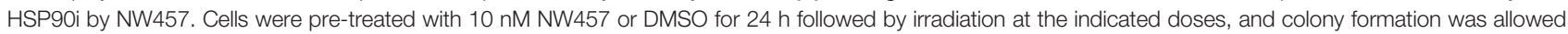
for $13 \mathrm{~d} \pm$ continuous NW457 treatment. Individual data points of 4 independent experiments are shown, linear-quadratic regression lines are superimposed, and overall curve comparison was performed by two-way ANOVA.

low concentrations of NW457 leads to destabilization of DDR regulators in various pathways and reduced DNA damage repair capacity. In consequence, the question arises whether this also translates into reduced clonogenic survival of GBM cells upon irradiation. To this end, LN229 and T98G cells were pre-treated with NW457 for $24 \mathrm{~h}$, irradiated at 0-8 Gy, and clonogenic survival was analyzed after $13 \mathrm{~d}$ incubation in the presence of NW457. As suggested by its marginal cytotoxicity (Supplementary Figure 1B), the effect of HSP90i monotherapy on clonogenic survival was modest in LN229 cells. In T98G cells it was clearly stronger, and for both cell lines this was statistically significant (Supplementary Figure 1C). Importantly, HSP90i by NW457 significantly reduced 
the clonogenic survival upon irradiation in both cell lines (Figure 1E), confirming our hypothesis that multi-target interference with DDR function by HSP90i at per se non-toxic doses suffices to sensitize resistant GBM cells to irradiation. Similar findings were very recently reported for other cancer entities $(62,63)$. Morphologically, the mode of cell death underlying reduced clonogenic survival upon HSP90i plus radiation was a highly disruptive, necrotic one which occurred after several rounds of aberrant mitosis and intermediate states of highly aneuploid cells with multiple and/or giant nuclei (Supplementary Movie File 1) (64).

\section{HSP90 Inhibition by NW457 Stimulates a Compensatory Transcriptional Upregulation of Genes Involved in Protein Production Accompanied by Downregulation of Genes Engaged in Survival Signaling, Cell Stemness, and Integrin Signaling}

Our results suggest-at first sight-that sensitization to radiotherapy upon HSP90i by NW457 derives from the downregulation of crucial DDR mediators on the protein level. Certainly, the immediate consequences of HSP90i affect the posttranslational level where abortive chaperoning leads to proteasomal degradation of HSP90 client proteins (65). Nevertheless, it is feasible to assume that this broad-range protein catabolytic remodeling can also stimulate complex responses on the transcriptome level which may contribute to radiosensitization as well. In order to address this question, we performed RNA sequencing analyses upon HSP90i by NW457 (10 nM) in LN229 and T98G cells. Differential gene expression analysis revealed an overt transcriptomic response in LN229 cells, and an attenuated but still detectable response in T98G cells (Supplementary Figure 2A). The overlap in up- or downregulated genes was rather small (Supplementary Figure 2B), possibly pointing towards a regulatory involvement of p53 (T98G have dominant negative $\mathrm{p} 53^{\mathrm{M} 237 \mathrm{I}}$, LN229 carry $\mathrm{p} 53^{\mathrm{P} 98 \mathrm{~L}}$ with unclear functionality but intact DNA binding domain, see Table 1 and Supplementary Table 2). Construction of a functional interaction (FI) network of the upregulated intersect genes revealed a clear activation of the heat shock response, comprising many chaperones and members of the heat shock protein family (Supplementary Figure 2C). This FI network appeared to be predominantly controlled by heat shock factor 1 (HSF1) as suggested by iRegulon analysis (Supplementary Figure 2D). For the common downregulated genes shared by LN229 and T98G cells, a smaller FI network was constructed, basically comprising elements of DNA repair, mitosis regulation, $\mathrm{NOTCH}$ signaling, and protein folding (Supplementary Figure 2E). iRegulon analysis suggested a rather heterogenous pattern of transcriptional regulators, including EP300, JUND, BCL3, and others (Supplementary Figure 2F).

Further geneset enrichment analysis (GSEA) of the transcriptomic alterations in LN229 cells upon HSP90i revealed positive enrichment of distinct MSigDB hallmark genesets comprising targets of MYC and E2F, as well as regulators of the G2/M cell cycle checkpoint (Supplementary Figure 3A). The FI network of the compiled leading edge genes allowed the conclusion that this was in principle a compensatory response to HSP90i treatment, because interaction clusters representing basic functions of RNA polymerase II transcription, mRNA processing and splicing, RNA transport, translation initiation, protein folding, rRNA processing, and ribosome biogenesis were identified. Moreover, clusters involved in cell cycle regulation (G2/M transition, G1/S transition, and mitosis) and DNA repair were observed among the leading edge genes. Without prior GSEA, the FI network of all significantly upregulated genes showed additional interaction clusters of transcription factor activation (AP1, GR, and p53), focal adhesion and organization of the extracellular matrix (ECM), the heat shock response, and signaling by small GTPases (RAS, RAP1, and RHO) (Supplementary Table 2).

In terms of transcriptional downregulation upon HSP90i, no significantly enriched MSigDB hallmark genesets (FDR $<0.1$ ) were observed in LN229 cells. However, on the level of significantly downregulated individual genes FI network construction revealed several interaction clusters whose decreased expression may contribute to radiosensitization by HPS90i. As such, clusters involved in survival signaling (EGFR and IGF1 signaling, PI3K/ $\mathrm{AKT} / \mathrm{mTOR}$ signaling) and maintenance of cell stemness (NOTCH signaling) represent potential candidates, as well as clusters orchestrating integrin signaling, ECM receptor interaction, and ECM organization (Supplementary Table 3).

\section{HSP90 Inhibition by NW457 Improves the Efficacy of Fractionated Radiotherapy in an Orthotopic, Syngeneic GBM Mouse Model}

In the next step, we examined the performance of HSP90i plus radiotherapy in vivo. We made use of a syngeneic orthotopic mouse GBM transplantation model with i.p. injection of an in vivo NW457 formulation and contrast-enhanced, conebeam (CB)CTbased, fractionated radiotherapy (43) (Figure 2). Importantly, we first recapitulated the basic in vitro experiments with GL261 cells, the murine cell line that was used for transplantation. This cell line showed a particularly strong downregulation of DDR proteins upon HSP90i (Supplementary Figures 4A, B) and did not tolerate permanent NW457 incubation in colony formation assays so that NW457 needed to be removed after the $24 \mathrm{~h}$ preincubation time (Supplementary Figures 4C, D). Nevertheless, this treatment was already sufficient to facilitate radiosensitization of GL261 cells which have been described to exhibit particularly high levels of intrinsic treatment resistance (66).

Upon transplantation of GL261 cells into the right hemispheres of C57BL/6 mice, tumor progression was monitored by contrastenhanced CBCT scans over time (Figure 2A). Starting at d7 after implantation, mice were subjected to CBCT-guided, fractionated radiotherapy with $2 \times 5 \times 2$ Gy using two contralateral beams at $3 \times 9 \mathrm{~mm}^{2}$ collimation (Figure 2B), and NW457 (or the vehicle control) was administered $24 \mathrm{~h}$ before each radiation treatment (10 or $50 \mu \mathrm{g} / \mathrm{g}$ i.p.). Tumor growth follow-up was accomplished by serial contrast-enhanced CBCT scans, and animals were sacrificed when reaching the pre-defined humane endpoints. Of note, $d 7$ CBCT scans confirmed that tumor volumes were statistically not 
significantly different across different treatment groups at the start of therapy (Supplementary Figure 5A).

Overall, the treatment was tolerated well, and no significant differences in body weight in response to the treatment were observed (Supplementary Figure 5B). Tumors of vehicle-treated animals grew exponentially, and monotherapy with HSP90i delayed tumor growth only marginally (Figure 2C). Fractionated radiotherapy exerted strong inhibitory effects on tumor growth, but responses were rather heterogeneous among the animals in this group. Additional HSP90i delayed tumor growth even further-yet compared to the effects observed in vitro, the in vivo performance was not as strong as expected. These findings basically mirrored the Kaplan-Meier survival analyses (Figure 2D). HSP90i in mono-agent settings had only minor impact on animal survival, although this reached statistical significance compared to the vehicle controls at $50 \mu \mathrm{g} / \mathrm{g}$ NW457. Upon radiotherapy alone, animals revealed clearly prolonged survival, albeit again with heterogenous responses. Survival times were further increased by additional HSP90i, although to a rather limited, yet statistically significant extent in case of $50 \mu \mathrm{g} / \mathrm{g}$ NW457. Interestingly, two animals of the combined modality group (radiotherapy $+50 \mu / g$ NW457) showed full tumor remission translating into persistent survival until the end of the experiment (Supplementary Figure 5C). In summary, these data indicate that HSP90i by NW457 can complement and improve the efficacy of fractionated radiotherapy in the used GBM in vivo model. Nevertheless, since the effects observed in vitro clearly outcompete the performance in vivo, further optimization of HSP90 inhibitor substances and/or treatment sequences would be needed.

\section{HSP90i by NW457 Attenuates Irradiation- Induced Hypermigration and Invasiveness of GBM Cells In Vitro and In Vivo}

Several previous studies have shown that non-lethal irradiation results in accelerated GBM cell migration-a phenomenon with implications for relapse and treatment failure $(67,68)$. We therefore examined, whether HSP90i by low-dose NW457 treatment does interfere with GBM cell migration. LN229 cells were treated with NW457 for $24 \mathrm{~h}$, irradiated at $3 \mathrm{~Gy}$, and their migratory behavior was analyzed in wound healing setups by

A
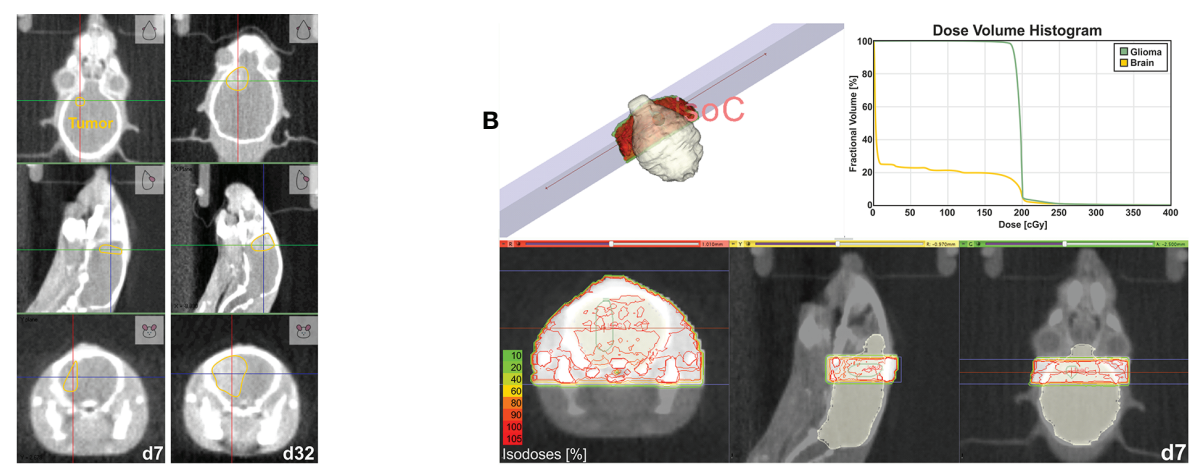

C
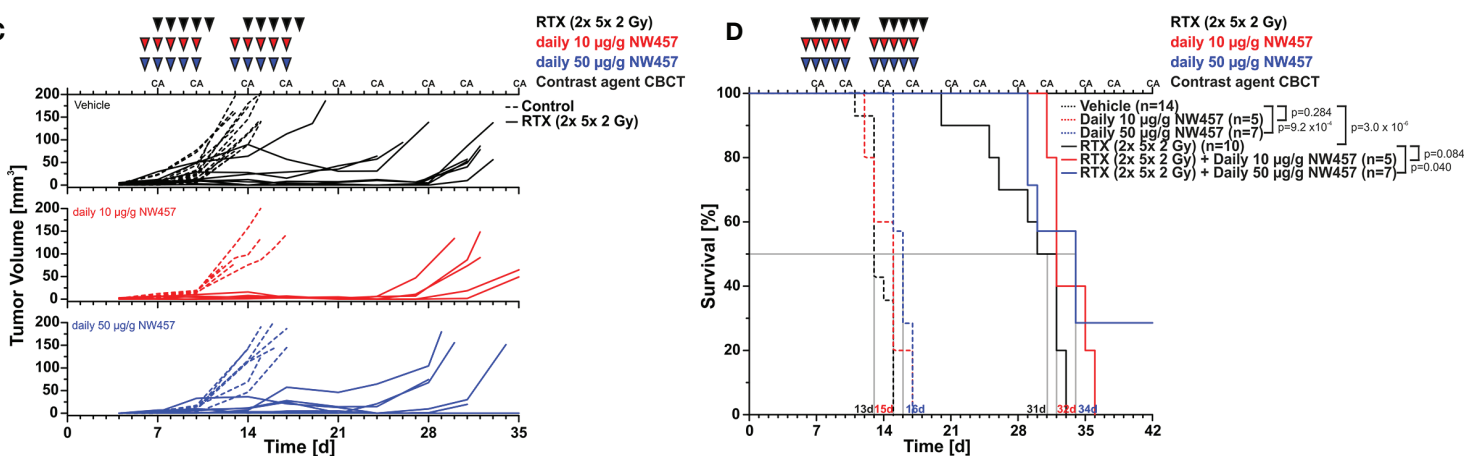

FIGURE 2 | HSP90i by NW457 improves the efficacy of fractionated radiotherapy in an orthotopic, syngeneic GBM mouse model. In vivo performance of NW457mediated HSP90i in combination with fractionated radiotherapy in orthotopically transplanted GL261 tumors. (A) Tumor localization and growth monitoring of orthotopically implanted GL261 cells in C57BL/6 mice were performed by contrast-enhanced CBCT scans and manual contouring. (B) Treatment plan and dose volume histogram. Two contralateral beams with $3 \times 9 \mathrm{~mm}^{2}$ collimation were used to administer $2 \times 5 \times 2$ Gy. (C) Treatment schedule and tumor growth curves. Six

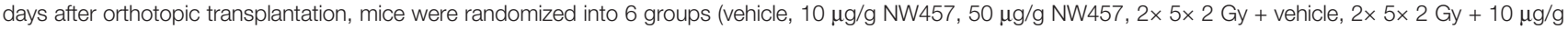

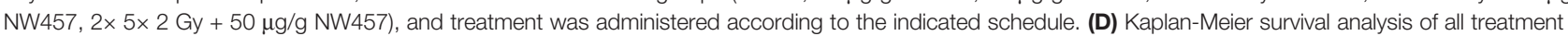
groups. Tumor-specific death was scored when mice showed pre-defined symptoms. p-values were obtained by log-rank test. 
live-cell imaging (Figure 3A and Supplementary Movies File 2). Migration was quantitated by the colonized area and the accumulated distance per cell over time as determined by tracking of at least 25 randomly picked cells per condition (Figures 3B-D). With both approaches, the basal migratory activity of LN229 cells was observed to be significantly increased by radiation at $3 \mathrm{~Gy}$, and this was almost completely reversed by pre-treatment with NW457. Thus, HSP90i, in addition to its radiosensitizing potential, does also efficiently counteract irradiation-induced hypermigration of GBM cells. In order to test whether this also holds true in vivo, we characterized the morphology of the tumors from our in vivo experiments. The aspect ratios of $\mathrm{L}$ axes (cranial-caudal, $90^{\circ}$ to beam axes) and $\mathrm{W}$ axes (left-right, $0^{\circ}$ to beam axes) were determined in contrast- enhanced CBCT scans of all mice at the day of sacrifice, and exemplary $3 \mathrm{D}$ reconstructions were generated (Figures $4 \mathrm{~A}-\mathrm{C}$ ). Tumors of mice from the radiotherapy-only group showed significantly distorted aspect ratios and caudal-cranially stretched $3 \mathrm{D}$ reconstructions, implying tumor progress orthogonally to the irradiation field. This effect was fully reversed by additional NW457 treatment. Histologically, tumors from irradiated mice revealed clearly more invasive borders than tumors from vehicle or NW457-only-treated mice, and also more and larger areas of hemorrhage (Figure 4D). Intriguingly, this morphotype was also fully reversed upon co-treatment with NW457, indicating that HSP90i does not only improve the therapeutic efficacy of radiotherapy but also counteracts GBM cell migration and tumor invasiveness in

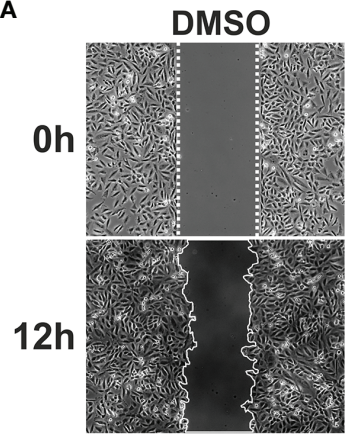

B

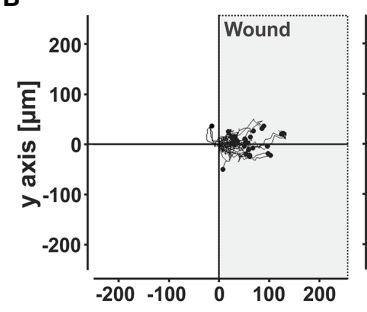

$3 \mathrm{~Gy}$

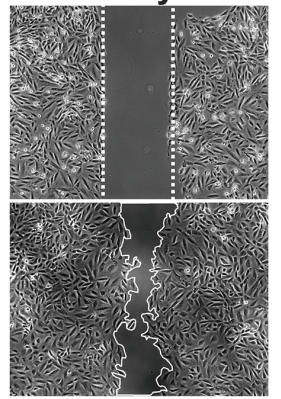

NW457

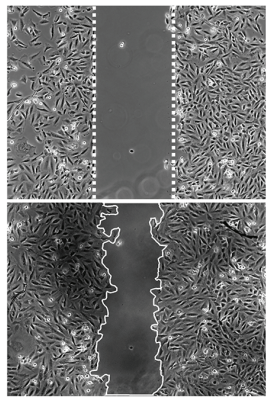

\section{Gy + NW457}
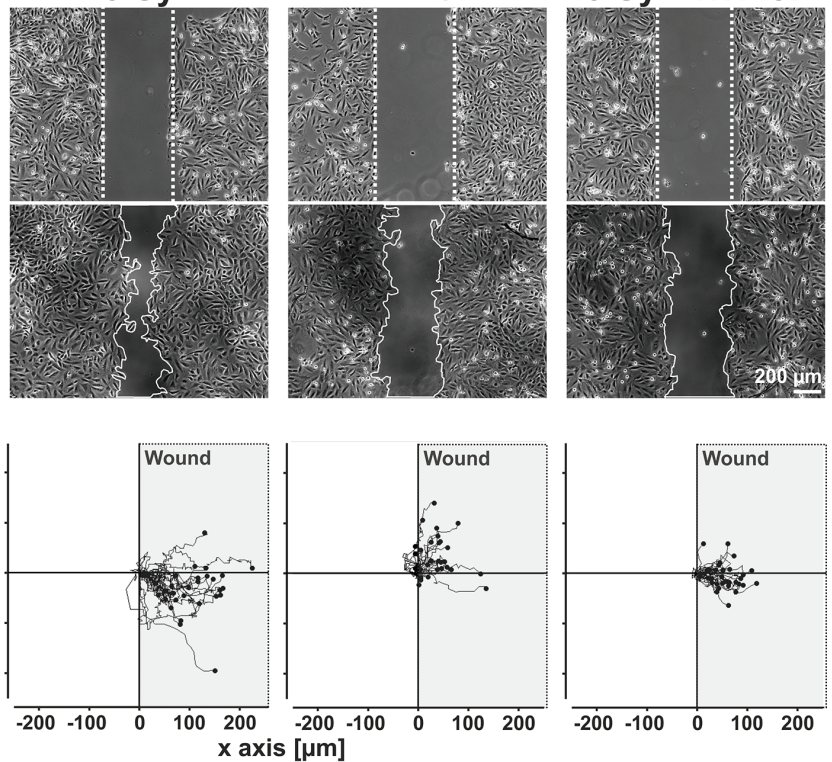
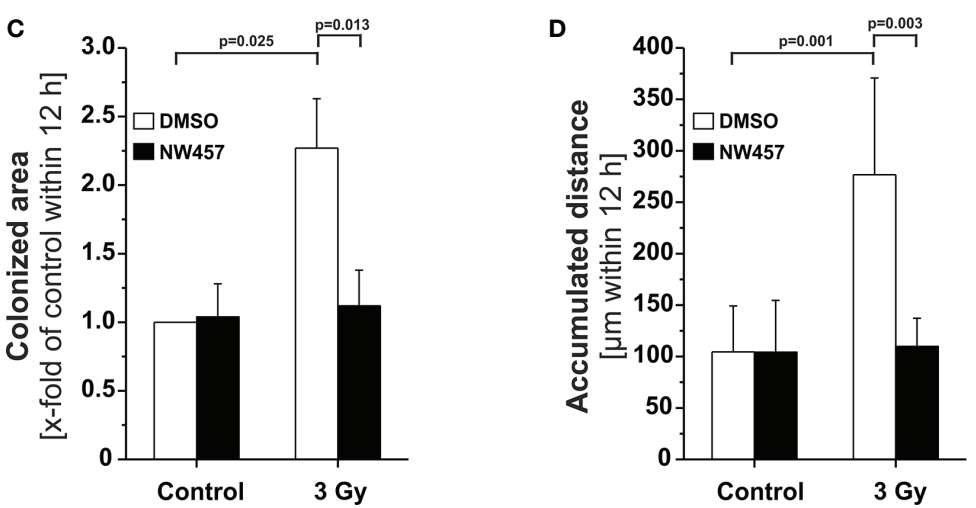

FIGURE 3 | HSP90i by NW457 counteracts GBM cell hypermigration in response to irradiation in vitro. (A) Live-cell imaging of the migratory behavior of GBM cells in wound healing assays. LN229 cells were seeded into Ibidi $\mu$-slides with silicon "wound" inserts, pre-treated with 30 nM NW457 or DMSO for 24 h, irradiated at 3 Gy where indicated, and analyzed by live-cell microscopy for $12 \mathrm{~h}$. "Wound" edges at the beginning and the end of the experiment are delineated by white dotted lines, and scale bar depicts 200 $\mu \mathrm{m}$. (B) Trajectory plots showing the migratory paths of at least 25 randomly picked and manually tracked cells from (A). (C) Relative quantification of the colonized area (depicted as $x$-fold values of controls) is shown as means \pm s.d. of 3 independent experiments. Group comparisons were performed by Student's $t$-tests. (D) Relative quantification of accumulated distances per cell. Means \pm s.d. of at least 25 randomly picked cells are shown. Group comparisons were performed by Student's $t$-tests. 
response to radiotherapy. These findings clearly strengthen the attractiveness of HSP90i as a partner for radiotherapy in combined modality settings.

\section{DISCUSSION}

Radiotherapy is a fundamental part of the standard of care for the treatment of glioblastoma (GBM) (69). However, treatment failure and (in-field) recurrence are frequent and form the basis for the dismal prognosis of this devastating disease (1). Significant advances in radiotherapy treatment and imageguidance technology as well as the addition of temozolomide (TMZ), a DNA alkylating chemotherapeutic drug, have led to modestly improved outcomes $(2,3)$, yet continued development remains urgently needed. GBM is characterized by a high level of inherent radioresistance which is considered to derive from overexpression of DNA damage response (DDR) genes and basally increased DDR activity $(6,8,9,45,46)$. In this context, the molecular chaperone HSP90 is of particular interest and represents a promising target for radiosensitization approaches, since several key regulators of the DDR are known to crucially depend on HSP90 folding assistance (70-75). However, in singleagent settings administration of HSP90 inhibitors was frequently associated with side effects of relevant severity, including gastrointestinal toxicity and hepatoxicity, because the concentrations needed to achieve anti-tumor effects-despite the relative selectivity for cancer versus normal cells-were rather high, and the employed substances exhibited suboptimal toxicity profiles and poor pharmacokinetic features (76). Intriguingly, quantitative mass spectrometric analyses revealed that pathways of the DDR are among the most sensitive ones in cancer cells that are perturbed by HSP90i already at very low inhibitor concentrations (22). Furthermore, a recent study showed that administration of very low, non-toxic doses of an HSP90 inhibitor of the third generation results in DDR protein disintegration in HNSCC and pancreatic cancer cells, while this was not observed in non-transformed, normal cells (62). This would allow targeting DNA damage repair mechanisms in cancer cells while not affecting the normal tissue and-in combination with radiotherapy-would imply a kind of biologically driven increase in radiation dose selectively at the tumor. Given that treatment-associated radionecrosis represents a major dose limiting factor in GBM radiotherapy, targeted radiosensitization of the tumor by HSP90i appears specifically attractive for this cancer entity, ideally in combination with modern high precision, image-guided radiotherapy (69).

In the present study, we report that treatment with very low concentrations of the pochoxime-derived HSP90 inhibitor NW457 which per se exhibit only limited cytotoxicity leads to
A
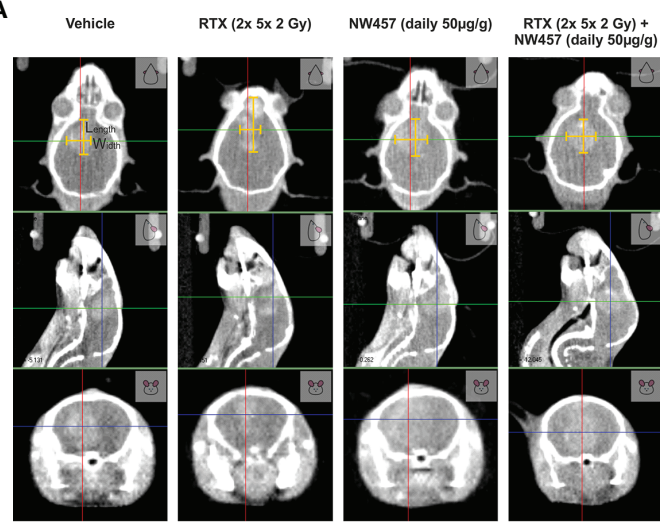

D

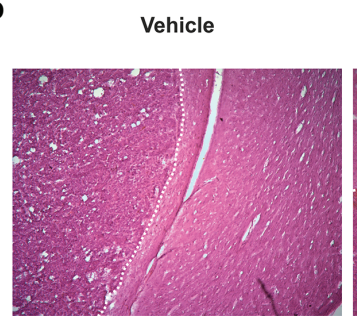

RTX (2x 5x 2 Gy)

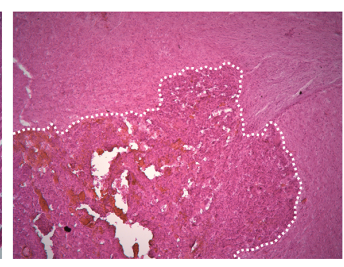

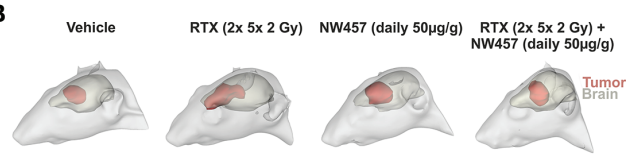

C

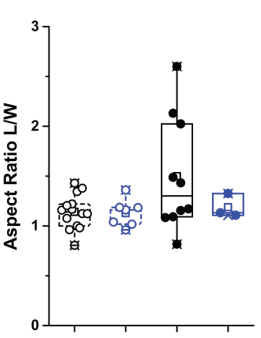

NW457 (daily 50 $\mathrm{gg} / \mathrm{g}$ )
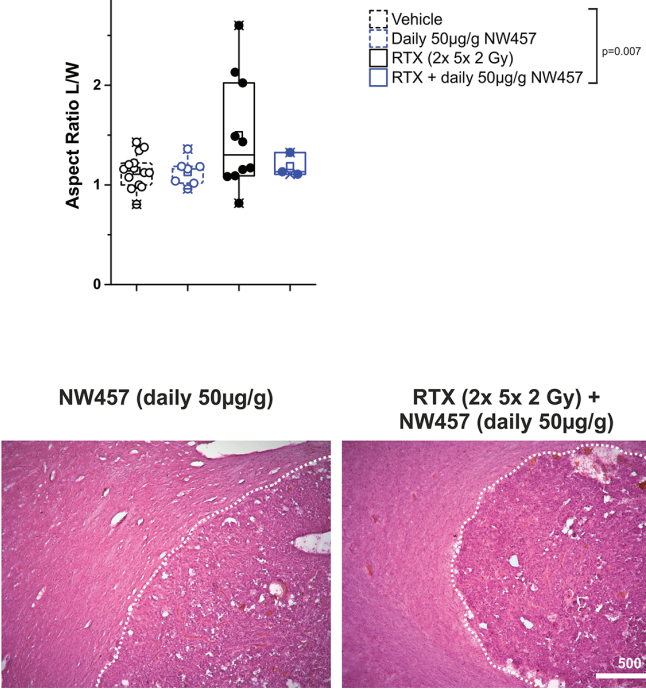

RTX + daily 50 Hgig 14057

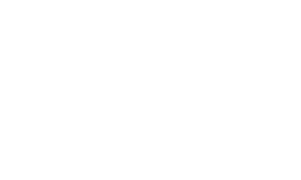

FIGURE 4 | HSP90i by NW457 attenuates GBM invasiveness in response to irradiation in vivo. Analysis of tumor morphology upon treatment at the time of animal sacrifice. (A) Contrast-enhanced CBCT scans of mice from different treatment groups. Tumor dimensions (width, length) are depicted by yellow bars in the coronal section (upper panels). (B) 3D reconstruction of tumors (red) and brains (grey) in mice from each treatment group as generated in 3D-Slicer. (C) Quantitative aspect ratio analysis of tumor length/width from each treatment group. p-value was calculated by one-way ANOVA (RTX vs. all other groups). (D) Hematoxylin/eosin (HE) stainings of tumors from all treatment groups. Tumor borders are highlighted by a dotted white line, and scale bar depicts $500 \mu \mathrm{m}$. 
DDR protein disintegration in GBM cells. We observed several key regulators of the DDR to be affected by HSP90i, previously published HSP90 client proteins as well as DDR regulators with so far unknown HSP90 dependence $(32,54-56,62)$. The cluster with the strongest decrease in protein levels upon HSP90i treatment in human and mouse GBM cell lines comprised CHK1, RAD51, DNA2, and NHEJ1. Accordingly, HSP90i represents a multi-target approach and affects various DDR pathways, including upstream checkpoint signaling (CHK1), double-strand break (DSB) repair by homologous recombination (RAD51), and non-homologous end-joining (NHEJ1), as well as crosslink repair and DNA replication (DNA2). This may explain why HSP90i is such a potent means of radiosensitization compared to mono-target approaches, for instance PARP inhibition $(26,77)$. Nevertheless, due to the correlative nature of our observations we cannot exclude that other mechanisms, such as the HSP90itriggered proteasomal degradation of non-DDR proteins or the observed transcriptional downregulation of various genes, for instance genes involved in survival and/or integrin signaling, contribute to radiosensitization (78-81).

Functionally, degradation of DDR regulators upon HSP90i was accompanied by delayed DNA damage repair kinetics and significantly impaired clonogenic survival upon irradiation. In vivo, HSP90i by NW457 augmented the efficacy of fractionated radiotherapy in an orthotopic, syngeneic GBM mouse model, both in terms of tumor progression and survival. However, the observed effects were not as strong as expected from the convincing in vitro results. This may be due to limited GBM penetration by the inhibitor in vivo, although the family of pochoxime-derived HSP90 inhibitors has been shown to exhibit favorable brain pharmacokinetic profiles (82). Nevertheless, a very recent study with an orthotopic patient-derived GBM model reported similar therapeutic efficacy of a related pochoximederived HSP90 inhibitor in combination with whole brain irradiation (83). So, inhibitor substances with improved brain pharmacokinetic profiles, optimized formulations and/or administration routes, and/or fine-tuned treatment sequences may help to fully develop the synergistic potential of HSP90i and radiotherapy for the treatment of GBM.

In addition to its radiosensitizing effects, we observed that HSP90i by NW457 did reverse irradiation-induced GBM cell hypermigration in vitro and GBM invasiveness in vivo. This is of relevant interest, since GBM cells which survive radiotherapy and evade the target volume of radiotherapy may drive tumor relapse and dissemination. Our findings are in line with other reports showing that HSP90i efficiently decreases migration and invasion of human GBM cell lines (84-86). Although the detailed mechanisms of action remain elusive, we assume that the downregulation of migration regulating proteins is of importance in this scenario. On the protein level, mediators of protein (tyrosine) kinases have been reported to be particularly sensitive to HSP90i, and these are crucial regulators of migration-relevant signaling cascades (22). Additionally, our study shows that HSP90i stimulated the transcriptional downregulation of several interaction clusters involved in migratory processes, including integrin signaling, ECM receptor interaction, and signaling by small and large
GTPases. HSP90i may thus offer a means to interfere with the highly infiltrative GBM phenotype which worsens with radiotherapy and represents another hallmark of this cancer entity contributing to its poor prognosis.

It should be noted, that HSP90i has also been shown to synergize with TMZ treatment in orthotopic models of GBM (87). This raises the question whether a triple combination of HSP90i and the current clinical standard of TMZ-based radiochemotherapy may improve the therapeutic outcome even further.

In conclusion, our study shows that HSP90i by low doses of NW457 potently interferes with the DDR in GBM cells leading to significant sensitization towards radiotherapy in vitro. The in vivo performance of this combined modality approach was less convincing than expected, although tumor growth was clearly delayed, survival was significantly prolonged, and radiationinduced invasive tumor morphology was reverted. Hence, our data reveal that the combination of HSP90i and radiotherapy is a promising strategy for GBM treatment whose performance needs to be further optimized by improved inhibitor substances, better formulations and/or administration routes, and fine-tuned treatment sequences.

\section{DATA AVAILABILITY STATEMENT}

The RNA sequencing datasets presented in this study can be found in online repositories. The names of the repository/ repositories and accession number(s) can be found here: NCBI GEO: GSE164717. All other datasets are available from the corresponding author upon reasonable request.

\section{ETHICS STATEMENT}

The animal study was reviewed and approved by the Regierung von Oberbayern.

\section{AUTHOR CONTRIBUTIONS}

$\mathrm{KL}, \mathrm{MN}, \mathrm{CB}, \mathrm{AAF}, \mathrm{HZ}, \mathrm{KU}, \mathrm{AKW}$ and $\mathrm{MO}$ conceived and designed the experiments. MO, VA, KS, LKi, BS, AN, JM, LKr, $\mathrm{NS}, \mathrm{JH}, \mathrm{KU}$ and KL performed the experiments and analyzed the data. NW provided the HSP90i NW457. MO and KL wrote the manuscript with support from KU and JH. All authors discussed the results, commented on and revised the manuscript.

\section{FUNDING}

This work was in part funded by the Bildungsministerium fuer Bildung und Forschung [02NUK047C and the German Cancer Consortium (DKTK)], the Deutsche Forschungsgemeinschaft 
(INST 409/126-1 FUGG, INST 409/20-1 FUGG, and INST 409/ 22-1 FUGG), and the FoeFoLe Program of the Medical Faculty of the LMU Munich.

\section{ACKNOWLEDGMENTS}

The murine glioblastoma cell line GL261 was obtained from the DCTP tumor repository (DTR, NCI, Frederick, MD, USA) in collaboration with Rainer Glass, Dept. of Neurosurgery,

\section{REFERENCES}

1. Fisher JL, Schwartzbaum JA, Wrensch M, Wiemels JL. Epidemiology of brain tumors. Neurol Clin (2007) 25:867-90, vii. doi: 10.1016/j.ncl.2007.07.002

2. Stupp R, Hegi ME, Mason WP, van den Bent MJ, Taphoorn MJ, Janzer RC, et al. Radiation Oncology, and G. National Cancer Institute of Canada Clinical Trials, Effects of radiotherapy with concomitant and adjuvant temozolomide versus radiotherapy alone on survival in glioblastoma in a randomised phase III study: 5-year analysis of the EORTC-NCIC trial. Lancet Oncol (2009) 10:459-66. doi: 10.1016/S1470-2045(09)70025-7

3. Stupp R, Mason WP, van den Bent MJ, Weller M, Fisher B, Taphoorn MJ, et al. Radiotherapy plus concomitant and adjuvant temozolomide for glioblastoma. N Engl J Med (2005) 352:987-96. doi: 10.1056/NEJMoa043330

4. Wilson TA, Karajannis MA, Harter DH. Glioblastoma multiforme: State of the art and future therapeutics. Surg Neurol Int (2014) 5:64. doi: 10.4103/ 2152-7806.132138

5. Davis ME. Glioblastoma: Overview of Disease and Treatment. Clin J Oncol Nurs (2016) 20:S2-8. doi: 10.1188/16.CJON.S1.2-8

6. Osuka S, Van Meir EG. Overcoming therapeutic resistance in glioblastoma: the way forward. J Clin Invest (2017) 127:415-26. doi: 10.1172/JCI89587

7. Taylor OG, Brzozowski JS, Skelding KA. Glioblastoma Multiforme: An Overview of Emerging Therapeutic Targets. Front Oncol (2019) 9:963. doi: 10.3389/fonc. 2019.00963

8. Mannino M, Chalmers AJ. Radioresistance of glioma stem cells: intrinsic characteristic or property of the 'microenvironment-stem cell unit'? Mol Oncol (2011) 5:374-86. doi: 10.1016/j.molonc.2011.05.001

9. Han X, Xue X, Zhou H, Zhang G. A molecular view of the radioresistance of gliomas. Oncotarget (2017) 8:100931-41. doi: 10.18632/oncotarget.21753

10. Alhajala HS, Nguyen HS, Shabani S, Best B, Kaushal M, Al-Gizawiy MM, et al. Irradiation of pediatric glioblastoma cells promotes radioresistance and enhances glioma malignancy via genome-wide transcriptome changes. Oncotarget (2018) 9:34122-31. doi: 10.18632/oncotarget.26137

11. Stanzani E, Martinez-Soler F, Mateos TM, Vidal N, Villanueva A, Pujana MA, et al. Radioresistance of mesenchymal glioblastoma initiating cells correlates with patient outcome and is associated with activation of inflammatory program. Oncotarget (2017) 8:73640-53. doi: 10.18632/oncotarget.18363

12. Bao S, Wu Q, McLendon RE, Hao Y, Shi Q, Hjelmeland AB, et al. Glioma stem cells promote radioresistance by preferential activation of the DNA damage response. Nature (2006) 444:756-60. doi: 10.1038/nature05236

13. Bhat KPL, Balasubramaniyan V, Vaillant B, Ezhilarasan R, Hummelink K, Hollingsworth F, et al. Mesenchymal differentiation mediated by NF-kappaB promotes radiation resistance in glioblastoma. Cancer Cell (2013) 24:331-46. doi: 10.1016/j.ccr.2013.08.001

14. Segerman A, Niklasson M, Haglund C, Bergstrom T, Jarvius M, Xie Y, et al. Clonal Variation in Drug and Radiation Response among Glioma-Initiating Cells Is Linked to Proneural-Mesenchymal Transition. Cell Rep (2016) 17:2994-3009. doi: 10.1016/j.celrep.2016.11.056

15. Jeon HY, Ham SW, Kim JK, Jin X, Lee SY, Shin YJ, et al. Ly6G(+) inflammatory cells enable the conversion of cancer cells to cancer stem cells in an irradiated glioblastoma model. Cell Death Differ (2019) 26:2139-56. doi: 10.1038/s41418-019-0282-0

16. Otomo T, Hishii M, Arai H, Sato K, Sasai K. Microarray analysis of temporal gene responses to ionizing radiation in two glioblastoma cell lines: up-regulation of DNA repair genes. J Radiat Res (2004) 45:53-60. doi: 10.1269/jrr.45.53
University Hospital, LMU Munich. The authors thank Manfred Felbermeier, Steffen Heuer, and Laura Holler for excellent technical assistance and animal husbandry.

\section{SUPPLEMENTARY MATERIAL}

The Supplementary Material for this article can be found online at: https://www.frontiersin.org/articles/10.3389/fonc.2021. 612354/full\#supplementary-material

17. Lewitzki V, Klement RJ, Kosmala R, Lisowski D, Flentje M, Polat B. Accelerated hyperfractionated radiochemotherapy with temozolomide is equivalent to normofractionated radiochemotherapy in a retrospective analysis of patients with glioblastoma. Radiat Oncol (2019) 14:227. doi: 10.1186/s13014-019-1427-5

18. Trone JC, Vallard A, Sotton S, Ben Mrad M, Jmour O, Magne N, et al. Survival after hypofractionation in glioblastoma: a systematic review and metaanalysis. Radiat Oncol (2020) 15:145. doi: 10.1186/s13014-020-01584-6

19. Liao G, Zhao Z, Yang H, Li X. Efficacy and Safety of Hypofractionated Radiotherapy for the Treatment of Newly Diagnosed Glioblastoma Multiforme: A Systematic Review and Meta-Analysis. Front Oncol (2019) 9:1017. doi: 10.3389/fonc.2019.01017

20. Sherriff J, Tamangani J, Senthil L, Cruickshank G, Spooner D, Jones B, et al. Patterns of relapse in glioblastoma multiforme following concomitant chemoradiotherapy with temozolomide. Br J Radiol (2013) 86:20120414. doi: $10.1259 /$ bjr.20120414

21. Pennisi R, Ascenzi P, di Masi A. Hsp90: A New Player in DNA Repair? Biomolecules (2015) 5:2589-618. doi: 10.3390/biom5042589

22. Sharma K, Vabulas RM, Macek B, Pinkert S, Cox J, Mann M, et al. Quantitative proteomics reveals that Hsp90 inhibition preferentially targets kinases and the DNA damage response. Mol Cell Proteomics (2012) 11:M111 014654. doi: 10.1074/mcp.M111.014654

23. Knighton LE, Truman AW. Role of the Molecular Chaperones Hsp70 and Hsp90 in the DNA Damage Response. In: AAA Asea, P Kaur, editors. Heat Shock Proteins in Signaling Pathways. Cham: Springer International Publishing (2019). p. 345-58. doi: 10.1007/978-3-030-03952-3_18

24. Lu X, Xiao L, Wang L, Ruden DM. Hsp90 inhibitors and drug resistance in cancer: the potential benefits of combination therapies of Hsp90 inhibitors and other anti-cancer drugs. Biochem Pharmacol (2012) 83:995-1004. doi: 10.1016/j.bcp.2011.11.011

25. Combs SE, Schmid TE, Vaupel P, Multhoff G. Stress Response Leading to Resistance in Glioblastoma-The Need for Innovative Radiotherapy (iRT) Concepts. Cancers (Basel) (2016) 8(1):15. doi: 10.3390/cancers8010015

26. Biau J, Chautard E, Verrelle P, Dutreix M. Altering DNA Repair to Improve Radiation Therapy: Specific and Multiple Pathway Targeting. Front Oncol (2019) 9:1009. doi: 10.3389/fonc.2019.01009

27. Barluenga S, Wang C, Fontaine JG, Aouadi K, Beebe K, Tsutsumi S, et al. Divergent synthesis of a pochonin library targeting HSP90 and in vivo efficacy of an identified inhibitor. Angew Chem Int Ed Engl (2008) 47:4432-5. doi: 10.1002/anie.200800233

28. Karthikeyan G, Zambaldo C, Barluenga S, Zoete V, Karplus M, Winssinger N. Asymmetric synthesis of pochonin $\mathrm{E}$ and $\mathrm{F}$, revision of their proposed structure, and their conversion to potent Hsp90 inhibitors. Chemistry (2012) 18:8978-86. doi: 10.1002/chem.201200546

29. Barluenga S, Fontaine JG, Wang C, Aouadi K, Chen R, Beebe K, et al. Inhibition of HSP90 with pochoximes: SAR and structure-based insights. Chembiochem (2009) 10:2753-9. doi: 10.1002/cbic.200900494

30. Kinzel L, Ernst A, Orth M, Albrecht V, Hennel R, Brix N, et al. A novel HSP90 inhibitor with reduced hepatotoxicity synergizes with radiotherapy to induce apoptosis, abrogate clonogenic survival, and improve tumor control in models of colorectal cancer. Oncotarget (2016) 7:43199-219. doi: 10.18632/ oncotarget. 9774

31. Ernst A, Hennel R, Krombach J, Kapfhammer H, Brix N, Zuchtriegel G, et al. Priming of anti-tumor immune mechanisms by radiotherapy is augmented by 
inhibition of heat shock protein. Front Oncol (2020) 10:1668 doi: 10.3389/ fonc. 2020.01668

32. Ernst A, Anders H, Kapfhammer H, Orth M, Hennel R, Seidl K, et al. HSP90 inhibition as a means of radiosensitizing resistant, aggressive soft tissue sarcomas. Cancer Lett (2015) 365:211-22. doi: 10.1016/j.canlet.2015.05.024

33. Unkel S, Belka C, Lauber K. On the analysis of clonogenic survival data: Statistical alternatives to the linear-quadratic model. Radiat Oncol (2016) 11:11. doi: 10.1186/s13014-016-0584-z

34. Hennel R, Brix N, Seidl K, Ernst A, Scheithauer H, Belka C, et al. Release of monocyte migration signals by breast cancer cell lines after ablative and fractionated gamma-irradiation. Radiat Oncol (2014) 9:85. doi: 10.1186/1748717X-9-85

35. Orth M, Unger K, Schoetz U, Belka C, Lauber K. Taxane-mediated radiosensitization derives from chromosomal missegregation on tripolar mitotic spindles orchestrated by AURKA and TPX2. Oncogene (2018) 37:52-62. doi: 10.1038/onc.2017.304

36. Dobin A, Davis CA, Schlesinger F, Drenkow J, Zaleski C, Jha S, et al. STAR: ultrafast universal RNA-seq aligner. Bioinformatics (2013) 29:15-21. doi: 10.1093/bioinformatics/bts635

37. Anders S, Pyl PT, Huber W. HTSeq-a Python framework to work with highthroughput sequencing data. Bioinformatics (2015) 31:166-9. doi: 10.1093/ bioinformatics/btu638

38. Zhu A, Ibrahim JG, Love MI. Heavy-tailed prior distributions for sequence count data: removing the noise and preserving large differences. Bioinformatics (2019) 35:2084-92. doi: 10.1093/bioinformatics/bty895

39. Subramanian A, Tamayo P, Mootha VK, Mukherjee S, Ebert BL, Gillette MA, et al. Gene set enrichment analysis: a knowledge-based approach for interpreting genome-wide expression profiles. Proc Natl Acad Sci USA (2005) 102:15545-50. doi: 10.1073/pnas.0506580102

40. Shannon P, Markiel A, Ozier O, Baliga NS, Wang JT, Ramage D, et al. Cytoscape: a software environment for integrated models of biomolecular interaction networks. Genome Res (2003) 13:2498-504. doi: 10.1101/ gr.1239303

41. Wu G, Haw R. Functional Interaction Network Construction and Analysis for Disease Discovery. Methods Mol Biol (2017) 1558:235-53. doi: 10.1007/978-14939-6783-4_11

42. Janky R, Verfaillie A, Imrichova H, Van de Sande B, Standaert L, Christiaens V, et al. iRegulon: from a gene list to a gene regulatory network using large motif and track collections. PloS Comput Biol (2014) 10:e1003731. doi: 10.1371/ journal.pcbi.1003731

43. Stegen B, Nieto A, Albrecht V, Maas J, Orth M, Neumaier K, et al. Contrastenhanced, conebeam CT-based, fractionated radiotherapy and follow-up monitoring of orthotopic mouse glioblastoma: a proof-of-concept study. Radiat Oncol (2020) 15:19. doi: 10.1186/s13014-020-1470-2

44. Wong J, Armour E, Kazanzides P, Iordachita I, Tryggestad E, Deng H, et al. High-resolution, small animal radiation research platform with $\mathrm{x}$-ray tomographic guidance capabilities. Int J Radiat Oncol Biol Phys (2008) 71:1591-9. doi: 10.1016/j.ijrobp.2008.04.025

45. Mukherjee B, McEllin B, Camacho CV, Tomimatsu N, Sirasanagandala S, Nannepaga $S$, et al. EGFRvIII and DNA double-strand break repair: a molecular mechanism for radioresistance in glioblastoma. Cancer Res (2009) 69:4252-9. doi: 10.1158/0008-5472.CAN-08-4853

46. Carruthers RD, Ahmed SU, Ramachandran S, Strathdee K, Kurian KM, Hedley A, et al. Replication Stress Drives Constitutive Activation of the DNA Damage Response and Radioresistance in Glioblastoma Stem-like Cells. Cancer Res (2018) 78:5060-71. doi: 10.1158/0008-5472.CAN-18-0569

47. Jackson SP, Bartek J. The DNA-damage response in human biology and disease. Nature (2009) 461:1071-8. doi: 10.1038/nature08467

48. Turgeon MO, Perry NJS, Poulogiannis G, Damage DNA. Repair, and Cancer Metabolism. Front Oncol (2018) 8:15. doi: 10.3389/fonc.2018.00015

49. Ishii N, Maier D, Merlo A, Tada M, Sawamura Y, Diserens AC, et al. Frequent co-alterations of TP53, p16/CDKN2A, p14ARF, PTEN tumor suppressor genes in human glioma cell lines. Brain Pathol (1999) 9:469-79. doi: 10.1111/ j.1750-3639.1999.tb00536.x

50. Bairoch A. The Cellosaurus, a Cell-Line Knowledge Resource. J Biomol Tech (2018) 29:25-38. doi: 10.7171/jbt.18-2902-002

51. Verhaak RG, Hoadley KA, Purdom E, Wang V, Qi Y, Wilkerson MD, et al. Integrated genomic analysis identifies clinically relevant subtypes of glioblastoma characterized by abnormalities in PDGFRA, IDH1, EGFR, and NF1. Cancer Cell (2010) 17:98-110. doi: 10.1016/j.ccr.2009.12.020

52. Brennan CW, Verhaak RG, McKenna A, Campos B, Noushmehr H, Salama SR, et al. The somatic genomic landscape of glioblastoma. Cell (2013) 155:462-77. doi: 10.1016/j.cell.2013.09.034

53. Esteller M, Garcia-Foncillas J, Andion E, Goodman SN, Hidalgo OF, Vanaclocha $\mathrm{V}$, et al. Inactivation of the DNA-repair gene MGMT and the clinical response of gliomas to alkylating agents. N Engl J Med (2000) 343:1350-4. doi: 10.1056/NEJM200011093431901

54. Dote H, Burgan WE, Camphausen K, Tofilon PJ. Inhibition of hsp90 compromises the DNA damage response to radiation. Cancer Res (2006) 66:9211-20. doi: 10.1158/0008-5472.CAN-06-2181

55. Dungey FA, Caldecott KW, Chalmers AJ. Enhanced radiosensitization of human glioma cells by combining inhibition of poly(ADP-ribose) polymerase with inhibition of heat shock protein 90. Mol Cancer Ther (2009) 8:2243-54. doi: 10.1158/1535-7163.MCT-09-0201

56. Arlander SJ, Eapen AK, Vroman BT, McDonald RJ, Toft DO, Karnitz LM. Hsp90 inhibition depletes Chk1 and sensitizes tumor cells to replication stress. J Biol Chem (2003) 278:52572-7. doi: 10.1074/jbc.M309054200

57. Zheng L, Meng Y, Campbell JL, Shen B. Multiple roles of DNA2 nuclease/ helicase in DNA metabolism, genome stability and human diseases. Nucleic Acids Res (2020) 48:16-35. doi: 10.1093/nar/gkz1101

58. Pawlowska E, Szczepanska J, Blasiak J. DNA2-An Important Player in DNA Damage Response or Just Another DNA Maintenance Protein? Int J Mol Sci (2017) 18(7):1562. doi: 10.3390/ijms18071562

59. Kumar S, Peng X, Daley J, Yang L, Shen J, Nguyen N, et al. Inhibition of DNA2 nuclease as a therapeutic strategy targeting replication stress in cancer cells. Oncogenesis (2017) 6:e319. doi: 10.1038/oncsis.2017.15

60. Liu W, Zhou M, Li Z, Li H, Polaczek P, Dai H, et al. A Selective Small Molecule DNA2 Inhibitor for Sensitization of Human Cancer Cells to Chemotherapy. EBioMedicine (2016) 6:73-86. doi: 10.1016/j.ebiom.2016.02.043

61. Ochi T, Wu Q, Blundell TL. The spatial organization of non-homologous end joining: from bridging to end joining. DNA Repair (Amst) (2014) 17:98-109. doi: 10.1016/j.dnarep.2014.02.010

62. Mehta RK, Pal S, Kondapi K, Sitto M, Dewar C, Devasia T, et al. Low-Dose Hsp90 Inhibitor Selectively Radiosensitizes HNSCC and Pancreatic Xenografts. Clin Cancer Res (2020) 26(19):5246-57. doi: 10.1158/10780432.CCR-19-3102

63. Lai TH, Mitchell S, Wu PJ, Orwick S, Liu C, Ravikrishnan J, et al. HSP90 inhibition depletes DNA repair proteins to sensitize acute myelogenous leukemia to nucleoside analog chemotherapeutics. Leuk Lymphoma (2019) 60:2308-11. doi: 10.1080/10428194.2019.1571197

64. Lauber K, Ernst A, Orth M, Herrmann M, Belka C. Dying cell clearance and its impact on the outcome of tumor radiotherapy. Front Oncol (2012) 2:116. doi: $10.3389 /$ fonc. 2012.00116

65. Trepel J, Mollapour M, Giaccone G, Neckers L. Targeting the dynamic HSP90 complex in cancer. Nat Rev Cancer (2010) 10:537-49. doi: 10.1038/nrc2887

66. Newcomb EW, Lymberis SC, Lukyanov Y, Shao Y, Schnee T, Devitt M, et al. Radiation sensitivity of GL261 murine glioma model and enhanced radiation response by flavopiridol. Cell Cycle (2006) 5:93-9. doi: 10.4161/cc.5.1.2271

67. Wild-Bode C, Weller M, Rimner A, Dichgans J, Wick W. Sublethal irradiation promotes migration and invasiveness of glioma cells: implications for radiotherapy of human glioblastoma. Cancer Res (2001) 61:2744-50.

68. Kargiotis O, Geka A, Rao JS, Kyritsis AP. Effects of irradiation on tumor cell survival, invasion and angiogenesis. J Neurooncol (2010) 100:323-38. doi: 10.1007/s11060-010-0199-4

69. Mann J, Ramakrishna R, Magge R, Wernicke AG. Advances in Radiotherapy for Glioblastoma. Front Neurol (2017) 8:748. doi: 10.3389/fneur.2017.00748

70. Kabakov AE, Kudryavtsev VA, Gabai VL. Hsp90 inhibitors as promising agents for radiotherapy. J Mol Med (Berl) (2010) 88:241-7. doi: 10.1007/ s00109-009-0562-0

71. Lauber K, Brix N, Ernst A, Hennel R, Krombach J, Anders H, et al. Targeting the heat shock response in combination with radiotherapy: Sensitizing cancer cells to irradiation-induced cell death and heating up their immunogenicity. Cancer Lett (2015) 368:209-29. doi: 10.1016/j.canlet.2015.02.047

72. Camphausen K, Tofilon PJ. Inhibition of Hsp90: a multitarget approach to radiosensitization. Clin Cancer Res (2007) 13:4326-30. doi: 10.1158/10780432.CCR-07-0632 
73. Lomeli N, Bota DA. Targeting HSP90 in malignant gliomas: onalespib as a potential therapeutic. Transl Cancer Res (2018) 7:6215-26. doi: 10.21037/ tcr.2018.03.05

74. van Ommeren R, Staudt MD, Xu H, Hebb MO. Advances in HSP27 and HSP90-targeting strategies for glioblastoma. J Neurooncol (2016) 127:209-19. doi: 10.1007/s11060-016-2070-8

75. Hintelmann K, Kriegs M, Rothkamm K, Rieckmann T. Improving the Efficacy of Tumor Radiosensitization Through Combined Molecular Targeting. Front Oncol (2020) 10:1260. doi: 10.3389/fonc.2020.01260

76. Butler LM, Ferraldeschi R, Armstrong HK, Centenera MM, Workman P. Maximizing the Therapeutic Potential of HSP90 Inhibitors. Mol Cancer Res (2015) 13:1445-51. doi: 10.1158/1541-7786.MCR-15-0234

77. Javle M, Curtin NJ. The role of PARP in DNA repair and its therapeutic exploitation. Br J Cancer (2011) 105:1114-22. doi: 10.1038/bjc.2011.382

78. Storch K, Sagerer A, Cordes N. Cytotoxic and radiosensitizing effects of FAK targeting in human glioblastoma cells in vitro. Oncol Rep (2015) 33:2009-16. doi: 10.3892/or.2015.3753

79. Toulany M, Dittmann K, Kruger M, Baumann M, Rodemann HP. Radioresistance of K-Ras mutated human tumor cells is mediated through EGFR-dependent activation of PI3K-AKT pathway. Radiother Oncol (2005) 76:143-50. doi: 10.1016/j.radonc.2005.06.024

80. Mohammadian Gol T, Rodemann HP, Dittmann K. Depletion of Akt1 and Akt2 Impairs the Repair of Radiation-Induced DNA Double Strand Breaks via Homologous Recombination. Int J Mol Sci (2019) 20(24):6316. doi: 10.3390/ ijms 20246316

81. Vehlow A, Klapproth E, Storch K, Dickreuter E, Seifert M, Dietrich A, et al. Adhesion- and stress-related adaptation of glioma radiochemoresistance is circumvented by betal integrin/JNK co-targeting. Oncotarget (2017) 8:4922437. doi: 10.18632 /oncotarget. 17480

82. Cha JR, St Louis KJ, Tradewell ML, Gentil BJ, Minotti S, Jaffer ZM, et al. A novel small molecule HSP90 inhibitor, NXD30001, differentially induces heat shock proteins in nervous tissue in culture and in vivo. Cell Stress Chaperones (2014) 19:421-35. doi: 10.1007/s12192-013-0467-2

83. Chen H, Gong Y, Ma Y, Thompson RC, Wang J, Cheng Z, et al. A BrainPenetrating Hsp90 Inhibitor NXD30001 Inhibits Glioblastoma as a
Monotherapy or in Combination With Radiation. Front Pharmacol (2020) 11:974. doi: 10.3389/fphar.2020.00974

84. Annamalai B, Liu X, Gopal U, Isaacs JS. Hsp90 is an essential regulator of EphA2 receptor stability and signaling: implications for cancer cell migration and metastasis. Mol Cancer Res (2009) 7:1021-32. doi: 10.1158/1541-7786.MCR-08-0582

85. Kim MS, Kwak HJ, Lee JW, Kim HJ, Park MJ, Park JB, et al. 17-Allylamino17-demethoxygeldanamycin down-regulates hyaluronic acid-induced glioma invasion by blocking matrix metalloproteinase- 9 secretion. Mol Cancer Res (2008) 6:1657-65. doi: 10.1158/1541-7786.MCR-08-0034

86. Gopal U, Bohonowych JE, Lema-Tome C, Liu A, Garrett-Mayer E, Wang B, et al. A novel extracellular Hsp90 mediated co-receptor function for LRP1 regulates EphA2 dependent glioblastoma cell invasion. PloS One (2011) 6: e17649. doi: 10.1371/journal.pone.0017649

87. Canella A, Welker AM, Yoo JY, Xu J, Abas FS, Kesanakurti D, et al. Efficacy of Onalespib, a Long-Acting Second-Generation HSP90 Inhibitor, as a Single Agent and in Combination with Temozolomide against Malignant Gliomas. Clin Cancer Res (2017) 23:6215-26. doi: 10.1158/1078-0432.CCR-16-3151

Conflict of Interest: All commercial rights on pochoximes (including epipochoxime F) were licensed by Nexgenic Pharmaceuticals (New York, NY, USA). NW consulted Nexgenic Pharmaceuticals, and received funding from Nexgenic Pharmaceuticals.

The remaining authors declare that the research was conducted in the absence of any commercial or financial relationships that could be construed as a potential conflict of interest.

Copyright $\odot 2021$ Orth, Albrecht, Seidl, Kinzel, Unger, Hess, Kreutzer, Sun, Stegen, Nieto, Maas, Winssinger, Friedl, Walch, Belka, Zitzelsberger, Niyazi and Lauber. This is an open-access article distributed under the terms of the Creative Commons Attribution License (CC BY). The use, distribution or reproduction in other forums is permitted, provided the original author $(s)$ and the copyright owner $(s)$ are credited and that the original publication in this journal is cited, in accordance with accepted academic practice. No use, distribution or reproduction is permitted which does not comply with these terms. 


\section{GLOSSARY}

\begin{tabular}{|c|c|}
\hline 53BP1 & p53-binding protein 1 \\
\hline ATM & ataxia telangiectasia mutated \\
\hline ATR & ataxia telangiectasia and Rad3 related \\
\hline BLM & Bloom syndrome helicase \\
\hline BRCA1 & breast cancer gene 1 \\
\hline BRCA2 & breast cancer gene 2 \\
\hline BRIP1 & BRCA1-interacting protein 1 \\
\hline CBCT & conebeam computed tomography \\
\hline CDKN1A & cyclin dependent kinase inhibitor $1 \mathrm{~A}$ \\
\hline $\mathrm{CHK} 1$ & checkpoint kinase 1 (gene symbol CHEK1) \\
\hline $\mathrm{CHK} 2$ & checkpoint kinase 2 (gene symbol CHEK2) \\
\hline DCLR1C & DNA cross-link repair protein $1 \mathrm{C}$ \\
\hline DNA2 & DNA replication ATP-dependent nuclease 2 \\
\hline DNA- & catalytic subunit of DNA-dependent protein kinase (gene symbol \\
\hline PKcs & PRKDC) \\
\hline DDR & DNA damage response \\
\hline DMSO & dimethyl sulfoxide \\
\hline DSB & double-strand break \\
\hline EORTC & European Organization for Research and Treatment of Cancer \\
\hline EXO1 & exonuclease 1 \\
\hline FANCA & Fanconi anemia complementation group A \\
\hline FEN1 & Flap endonuclease 1 \\
\hline FCS & fetal calf serum \\
\hline GBM & glioblastoma \\
\hline$\gamma H 2 A X$ & phosphorylated histone variant 2AX (pS139) \\
\hline HE & hematoxylin and eosin \\
\hline HSP70 & heat shock protein 70 \\
\hline HSP90 & heat shock protein 90 \\
\hline HSP90i & heat shock protein 90 inhibition \\
\hline KU70 & ATP-dependent DNA helicase subunit KU70 (gene symbol XRCC6) \\
\hline KU80 & ATP-dependent DNA helicase subunit KU80 (gene symbol XRCC5) \\
\hline LIG4 & DNA-ligase 4 \\
\hline MGMT & O6-methylguanine-DNA-methyltransferase \\
\hline MRE11 & meiotic recombination protein 11 \\
\hline MRN & MRE11-RAD50-NBN \\
\hline NBN & Nibrin \\
\hline $\mathrm{NClC}$ & national cancer information center \\
\hline NHEJ1 & non-homologous end joining protein 1 \\
\hline p21 & cyclin-dependent kinase inhibitor p21 (gene symbol CDKN1A) \\
\hline p53 & tumor suppressing protein p53 (gene symbol TP53) \\
\hline PALB2 & partner and localizer of BRCA2 \\
\hline PARP1 & poly(ADP-ribose)-polymerase 1 \\
\hline PARP2 & poly(ADP-ribose)-polymerase 2 \\
\hline PS & pencillin/streptomycin \\
\hline RAD50 & DNA repair protein RAD50 \\
\hline RAD51 & DNA repair protein RAD51 \\
\hline RAD52 & DNA repair protein RAD52 \\
\hline RAD54 & DNA repair protein RAD54 \\
\hline RBBP8 & Retinoblastoma-binding protein 8 \\
\hline RPA1 & replication protein $\mathrm{A} 1$ \\
\hline qRT-PCR & quantitative realtime reverse transcription polymerase chain reaction \\
\hline RTX & radiotherapy \\
\hline STR & short tandem repeat \\
\hline $\mathrm{TMZ}$ & temozolomide \\
\hline XRCC1-5 & $\mathrm{x}$-ray repair cross-complementing protein 1-5 \\
\hline
\end{tabular}

